Article

\title{
Non Isothermal Crystallization Kinetics and Isothermal Decomposition of Poly(Ethylene-Co- Vinylalcohol/Poly(D,L-Lactic-Co-Glycolic Acid) Blend
}

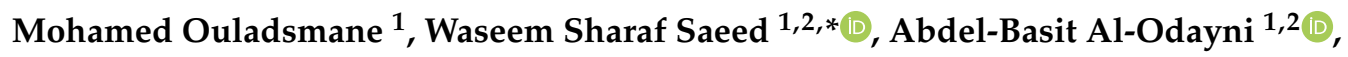 \\ Ahmed Yacine Badjah Hadj Ahmed ${ }^{1}$, Abdulaziz Ali Alghamdi ${ }^{1}$, Abdullah Al-Kahtani ${ }^{1}$ (D) and \\ Taieb Aouak 1,* \\ 1 Chemistry Department, College of Science, King Saud University. P. O. Box 2455, Riyadh 11451, \\ Saudi Arabia; mouladsmane@ksu.edu.sa (M.O.); aalodayni@ksu.edu.sa (A.-B.A.-O.); \\ ybadjah@ksu.edu.sa (A.Y.B.H.A.); aalghamdia@ksu.edu.sa (A.A.A.); akahtani@ksu.edu.sa (A.A.-K.) \\ 2 Engineer Abdullah Bugshan Research Chair for Dental and Oral Rehabilitation, College of Dentistry, \\ King Saud University, Riyadh 11545, Saudi Arabia \\ * Correspondence: wsaeed@ksu.edu.sa (W.S.S.); taouak@ksu.edu.sa (T.A.)
}

Received: 28 April 2020; Accepted: 25 May 2020; Published: 26 May 2020

\begin{abstract}
A series of poly(ethylene-co-vinylalcohol)(PE-VOL)/poly(D,L-lactic-co-glycolic acid (PD,L-LGA) blends with different compositions was prepared by solution casting, and its miscibility was proved through viscosimetry and differential scanning calorimetry (DSC) methods through a positive value of $\alpha$ (San et al. Eq.) and negative value of $\chi 1,2$ (Nishi-Wang Equation). XRD analysis of the PE-VOL/PD,L-LGA system revealed a homogeneous distribution of PE-VOL molecules aggregated in the PD,L- LGA matrix and the crystalline structure of the semi crystalline copolymer was conserved in the blend in aggregated form. It also revealed that the amorphous copolymer dispersed in the blend acted as a weak nucleating agent. The non-isothermal crystallization kinetics of neat semi-crystalline copolymer and the blend was used to describe the crystallization process using the Ozawa approach. The thermal stability of these materials was investigated by the thermal gravimetry analysis. The isothermal decomposition of copolymers and their blend were carried out by high resolution mass spectrometry using direct-analysis-in-real-time method. Relevant results that could highlight the miscible character of this blend are revealed through comparison of the different fragments resulting from the decomposition of the blend with those of the pure components.
\end{abstract}

Keywords: Poly(ethylene-co-vinylalcohol)/poly(D,L-lactic-co-glycolic acid) blend; non-isothermal crystallization; isothermal decomposition; mass spectrometry used at direct -analysis-in-real time

\section{Introduction}

During the last two decades, a significant number of works have emerged relating to the preparation and study of the properties of polymeric materials with a view to their use as scaffolding in the biomedical field. Among the investigations reported, very few articles have been published on the relationship between the crystallization behavior, crystallinity, and physical and mechanical properties of polymeric material on its biogedradation rate. Indeed, it is well known that the biodegradation rate is slower in a semi-crystalline polymer compared with that in homocrystal form [1,2]. Other authors have reported that biodegradation is depressed in polylactide stereo-complex crystals compared to that in homo-crystals [3,4]. Consequently, a more detailed study of the crystallinity and the way in which the crystals develop in the polymer matrix is essential in order to better define the biodegradable property of polymer as a candidate for use as scaffold in the biomedical field. 
Poly(ethylene-co-vinylalcohol)(PE-VOL) is a flexible semi-crystalline thermoplastic. This semi-crystalline copolymer is characterized by its excellent thermal stability [5], chemical resistance [6], good mechanical properties [7], biodegradability, and non-toxicity [8]. The presence of a large number of hydroxyl groups in this copolymer allows it to degrade easily in enzymatic media [9-12]. The presence of hydrophobic ethylene units in the PE-VOL main chain sufficiently reduces its high swelling capacity in water, which provides it the good performance in the biomedical domain, particularly in drug delivery and scaffold development. PE-VOL is fabricated by a two-step process: (i) by copolymerization of vinyl acetate with ethylene; (ii) then by hydrolysis of the vinyl acetate units of the copolymer obtained to obtain the final product. In the biomedical field, this copolymer is used by Guerra et al. [8] to investigate the activation of human plasma prekallikrein as a hemo-compatibility test. Matsumoto et al. [13] applied PE-VOL as a membrane to investigate the hemodialysis field.

According to different other investigations reported in the literature, when PE-VOL is employed as a membrane in the biomedical field, it adsorbs few plasma proteins, interacts weakly with cell components in blood [14,15], and inhibits the adsorption of plasma proteins, thereby inhibiting the body's reaction to the membrane [16,17]. Young et al. [18] developed membranes based on PE-VOL with smooth and particulate morphologies for neuronal culture application.

PD,L-LGA is principally synthesized by two distinct methods: the direct polycondensation between glycolic acid and lactic acid, thus producing a copolymer characterized by low molecular weight [17-20]. The lateral methyl groups present in the lactic acid units of this copolymer increase its hydrophobic character and subsequently control its biodegradability. The hydrolysis of PD,L-LGA leads to modifications of its specific parameters such as the molar mass, water content, and mechanical and thermal properties [21]. Consequently, PD,L-LGA is composed of two distinct sequences; the first one is formed from lactic acid (LA) and the second from glycolic acid (GA) units. Consequently, the LA unit sequence includes sequence includes three enantiomers due to the presence of an asymmetric carbon in the LA unit. The LA unit sequence comprises three enantiomers resulting from the presence of an asymmetric carbon in its structure, which are L-PLA, D-PLA, and D, L-PLA. L-PLA and D-PLA enantiomers have a semi crystalline structure, while the D, L-PLA is characterized by an amorphous structure because of the irregularity of the $L$ and $D$ units in the polymer chain [22]. The racemic form is more preferred as a carrier [23] in the drug-carrier system because of the homogenous distribution of drug particles in this specific material. PD,L-LGA based drug delivery devices have been experimented for tissue engineering [24-26], vascular engineering [27-30], nerve regeneration [19,31], cartilage tissue engineering [5,32-34], and bone tissue engineering [12,35-37]. PD,L-LGA has been the subject of several publications in the biomedical field. Indeed, because of its biocompatibility and biodegradability, this copolymer was used as carrier in the drug delivery domain and as materials in tissue engineering applications. The combination of the PE-VOL with PD,L-LGA undoubtedly gives new hybrid materials characterized by intermediate properties. By controlling the ratio of the components, the new resulted properties of the materials can be easily adapted to the desired functions. Despite the highly desirable properties of these copolymers and the new properties that can be generated by their combinations, we have only found the presence of a very limited number of works published in the literature on a blend involving one of these two copolymers, and still very few subjects on their crystalline properties and on the crystallization processes. Note that the mechanical and thermal properties of a semi-crystalline polymer depend on its crystalline mode and its crystallization mechanism. Among the most relevant articles found in the literature on the crystallization of a blend involving PE-VOH was that of Luo et al. [38]. These authors have studied the blend of two semi-crystalline polymers, $\mathrm{PE}-\mathrm{VOH}$ and polypropylene (PP) obtained by fusion using poly(propylene-graft-maleic anhydride as compatibilizer.

The isothermal crystallization kinetics was used as method to carry out this study and the results obtained were an increase of the overall rate of the crystallization process of PP by incorporating of PE-VOL in the blend and this copolymer acted as an effective nucleating agent for PP. The X-ray diffraction of neat PP and blends revealed identical crystal structure. Recently, the non-isothermal 
crystallization of a blend involved PE-VOL and poly(valerolactone) prepared by solvent casting method was investigated by our research group [39]. It was revealed that the miscibility of this blend was miscible in all compositions and at certain temperatures the crystallization rate decrease 2- to 4-fold compared with those of pure components. Zhu et al. [40] investigate the non-isothermal crystallization of PE-VOL combined with poly(oxypropylene) diamine intercalated montmorrilonite prepared by solvent casting method. These authors used the Mo and Ozawa methods to study the non-isothermal crystallization process and the results obtained revealed a perfect description when the Mo's method is used. The incorporation of the clays nanoparticles in the blend matrix had a heterogeneous nucleation effect to accelerate the crystallization of the PE-VOL despite hampering the macromolecular chains motion. Note that during our literature survey, we did not come across any work done on the crystalline behavior of a semi-crystalline polymer blended with the PD,L-LGA of amorphous structure. Given the importance of the properties of the copolymers cited above their implications in the blends with other polymers undoubtedly make it possible to develop new materials which could be candidates as scaffolds in the biomedical field. In order to understand the structure-properties relationship of these materials, we were very interested to know the crystalline behavior and the crystallization mechanism of this semi-crystalline copolymer when is combined with amorphous PD,L-LGA in a miscible blend.

In this way a series of blends based on semi-crystalline PE-VOL and amorphous PD,L-LGA blend with different compositions was prepared by solvent casting method in which the miscibility, crystalline behaviors, and non-isothermal crystallization kinetics of PE-VOL in the blend were widely studied using viscosimetry, X-RD, and DSC techniques. The thermal stability and the fragments generated from isothermal decomposition of the blend and its components are investigated by thermogravimetry analysis (TGA) and direct analysis in real time mass spectrometry (DART-ToF-MS).

\section{Experimental}

\subsection{Materials}

Poly(ethylene-co-vinylalcohol) (PE-VOL) (28 mole\% of ethylene unit) and amorphous poly(D,L-lactic-co-glycolic acid) (PD,L-LGA) (PL:GA equal ratios, 65,000 $\mathrm{g} \mathrm{mol}^{-1}$ ) were supplied by Purac (Groningen, The Netherlands). Dimethylformamide (DMF) (99\% purity) was purchased from Sigma-Aldrich (Taufkirchen, Germany). Polymers and the solvent were used without further purification.

\subsection{Blend Preparation}

PE-VOL/PD,L-LGA blend was prepared by dissolving $10 \mathrm{wt} \%$ of each copolymer in DMF until a perfectly clear and transparent solution was obtained. This solution was then poured onto a perfectly horizontal Teflon plate for $48 \mathrm{~h}$ in order to vaporize the solvent and obtain a film of homogeneous thickness. The film obtained was then dried in the oven under vacuum maintained at $50{ }^{\circ} \mathrm{C}$ for $24 \mathrm{~h}$ to completely extract the residue of the DMF clustered in the polymer film. PE-VOH/PD,L-LGA films containing 10, 25, 50, 75 and $90 \mathrm{wt} \%$ were prepared by the same method and the preparation conditions are gathered in Table 1 . The thickness of each film obtained was measured by a Digital Micrometer Mitutoyo 293-340-30.

Table 1. Preparation conditions of PE-VOH/PD,L-LGA blends.

\begin{tabular}{ccccccc}
\hline \multirow{2}{*}{ System } & \multicolumn{2}{c}{ PE-VOL } & \multicolumn{2}{c}{ PD,L-LGA } & DMF & \multirow{2}{*}{ Blend Appearance } \\
\cline { 2 - 5 } & $\mathbf{( g )}$ & $\mathbf{( w t} \%)$ & $\mathbf{( g )}$ & $\mathbf{( w t} \%)$ & $\mathbf{( m L )}$ & \\
\hline PE-VOL/PD,L-LGA10 & 0.50 & 10 & 4.50 & 90 & 20 & Single phase \\
PE-VOL/PD,L-LGA25 & 1.25 & 25 & 3.75 & 75 & 20 & Single phase \\
PE-VOL/PD,L-LGA50 & 2.50 & 50 & 2.50 & 50 & 20 & Single phase \\
PE-VOL/PD,L-LGA75 & 3.75 & 75 & 1.25 & 25 & 20 & Single phase \\
PE-VOL/PD,L-LGA90 & 4.50 & 90 & 0.50 & 10 & 20 & Single phase \\
\hline
\end{tabular}




\subsection{Analyses}

The viscosity measurements of the blend and their neat components were carried out in DMF at $40{ }^{\circ} \mathrm{C}$ employing a viscosimeter Ubbelohde Scott Gerate type Avs 310 and the method used to reach this goal was in detail described in the literature by Soria et al. [41].

X-ray diffraction patterns of copolymers and their neat components were obtained using a BRUKER D8 advance diffractometer and a run with $\mathrm{CuK} \alpha$ radiation of $40 \mathrm{kV}$ and $40 \mathrm{~mA}$ at a scanning rate $2 \theta$ of $2^{\circ} \mathrm{min}^{-1}$. DSC analysis of blends and their components were carried out on a Shimadzu DSC $60 \mathrm{~A}$ (Kyoto, Japan) previously calibrated with indium. Samples containing between 8 and $15 \mathrm{mg}$ of blend or neat copolymers were packed in aluminum DSC pan then placed in the DSC cell. Samples were scanned between -30 and $240{ }^{\circ} \mathrm{C}$ at a heating rate of $10^{\circ} \mathrm{C} \mathrm{min}^{-1}$. The glass transition temperatures, $T_{g} \mathrm{~s}$, and those of fusion, $T_{m} \mathrm{~s}$, of polymer samples were deduced from the thermograms obtained from the middle of the first point of transition and the top of the endothermic peak corresponding to the fusion, respectively.

To destroy all the nuclei that can act as crystal grains the heating of the samples was then maintained for $5 \mathrm{~min}$ at $200{ }^{\circ} \mathrm{C}$ before being cooled. These specimens were then cooled down to $50{ }^{\circ} \mathrm{C}$ at constant rates of $10,12.5,15.0,17.5$, and $20^{\circ} \mathrm{C} \mathrm{min}^{-1}$, respectively. To maintain a uniform thermal history in all samples, the thermal traces were considered by the data of the second run, after quenching above the glass transition temperature. Note that the results obtained were perfectly reproducible after three runs and no degradation of samples was detected on the thermograms obtained during all the heating process. The non-degradation of the samples was also confirmed by a solubility test on the samples after DSC analysis. The TGA thermograms of net copolymers and their blends were traced on a Shimadzu TGA60 under a stream of nitrogen. Samples weighing between $10 \mathrm{~g}$ and $14 \mathrm{~g}$ were carefully placed in TGA aluminum pans then scanned by heating from $25^{\circ} \mathrm{C}$ to $600{ }^{\circ} \mathrm{C}$ at a constant heating rate of $20^{\circ} \mathrm{C} \cdot \mathrm{min}^{-1}$. The fragments resulted from the isothermal decomposition of blends and their pure components were analyzed by an Accu-ToF LC-plus JMS-T100 LP mass spectrometer JEOL (Tokyo, Japan) working with a direct-analysis-in-real-time (DART) ion source (Ion Sense, Saugus, MA, USA). The samples were used without any prior preparation. The fragments resulted from the decomposition process were evaporated in a stream of He atmosphere heated at constant temperatures ( 350 and $380^{\circ} \mathrm{C}$ ). Heated helium/Vapor mixture was then ionized by excited metastable helium atoms, before entering the ion source of the time-of-flight mass spectrometer. All the samples were analyzed by DART-ToF-MS using Accu-TOF mass spectrometer acquired from JEOL (Tokyo, Japan). The experimental conditions were: vacuum level $1.3 \times 10^{-5} \mathrm{~Pa}$, He used as a heating and ionization gas, ring lens with a voltage of $4 \mathrm{~V}$, peaks voltage of $500 \mathrm{~V}$, and the mass resolution was ranged between 3600 and 4900 .

\section{Results and Discussion}

\subsection{Viscosimetry Analysis}

The specific viscosities, $\eta_{s p}$, of copolymers and blends solutions were determined at different concentrations in DMF from the efflux time measurements. The intrinsic viscosity of the blend as well as those of their components, $[\eta]$, was deduced from the intercept obtained by extrapolation of the linear curve indicating the variation of $\eta_{s p}$ as a function of its concentration obtained according to the Huggins equation: [42]

$$
\eta_{s p}=[\eta] C+k[\eta]^{2} C^{2}
$$

where $C$ and $k$ symbolize the concentration of neat copolymer or blend in DMF and the Huggins-constant of the polymeric solution, respectively. The viscosimetric parameter, $\alpha$, which provided the interaction 
intensity between the polymer chains of different natures in the blend, was estimated using the San et al. Equation (2) [43]:

$$
\alpha=k_{b}-\frac{k_{2}[\eta]_{2}^{2} w_{2}^{2}+k_{3}[\eta]_{3}^{2} w_{3}^{2}+2 \sqrt{k_{2} k_{3}}[\eta]_{2}[\eta]_{3} w_{2} w_{3}}{\left([\eta]_{2} w_{2}+[\eta]_{3} w_{3}\right)^{2}}
$$

where $k_{b}$ and $k_{i}$ are the Huggins-constant of the blend and that of the component $(i),[\eta]_{i}$ and $w_{i}$ are the intrinsic viscosity and the weight fraction of the copolymer $(i)$ in the solution, respectively. According to the Sun et al. approach, a miscible blend is characterized by a positive or nil $\alpha$ value which indicates the presence of attractive forces between the two different chains in the blend in solution. Inversely, a negative $\alpha$ value reveals repulsive forces leading to the phase's separation. Indeed, the results of the $\alpha$ interactional parameter obtained as illustrated in Table 2 reveals positive values for PE-VOL/PD,L-LGA system in all the investigated composition range. So, the miscibility of this pair of copolymers was due to the hydrogen bonds interactions developed between the different copolymeric chains.

Table 2. Intrinsic viscosity $([\eta])$, Huggins-constant $(k)$ and interaction parameter $(\alpha)$ of PE-VOL, PD,L-LGA and their blends with different compositions.

\begin{tabular}{cccc}
\hline System & {$[\boldsymbol{\eta}] \mathbf{( d L / g )}$} & $\boldsymbol{k}$ & $\boldsymbol{\alpha}$ \\
\hline PE-co-VAL & 0.62 & 1.626 & - \\
PE-VOL/PD,L-LGA10 & 0.58 & 8.87 & 3.12 \\
PE-VOL/PD,L-LGA25 & 0.52 & 6.67 & 3.42 \\
PE-VOL/PD,L-LGA50 & 0.40 & 6.04 & 4.80 \\
PE-VOL/PD,L-LGA75 & 0.38 & 5.44 & 4.50 \\
PE-VOL/PD,L-LGA90 & 0.32 & 3.92 & 3.20 \\
PD,L-LGA & 0.27 & 0.548 & - \\
\hline
\end{tabular}

The X-RD spectrograms taken for the pure PE-VOL and PE-VOL/PD,L-LGA systems with different compositions are showed in Figure 1. The spectrogram of pure PD,L-LGA containing equal an PLA/PLG composition revealed the absence of any peaks, indicating an amorphous structure of this copolymer, as reported in the literature [44]. In contrast, the spectrogram of the pure PE-VOL revealed three typical peaks at $19.86,22.5$, and $41.232 \theta$ corresponding to the reflexion planes attributed to the crystalline monoclinic form of this copolymer containing $72 \mathrm{~mol} \%$ of vinylalcohol unit [45]. Indeed, according to Carrada et al [46]. the crystalline form of PE-VOL depends on the ethylene/vinylalcohol composition and also on the crystallization conditions. It was also reported by the same investigators that the final crystallographic properties of PE-co-VAL can be determined through the control of temperature during cooling in the final stage of the crystallization process. They revealed that at slow cooling rates, different types of crystal structures are obtained, whereas at fast cooling rates or quenching (e.g., at $100^{\circ} \mathrm{C} / \mathrm{min}$ ), only the orthorhombic structure is obtained for all ethylene/vinylalcohol compositions. The X-RD patterns of the PE-VOL/PD,L-LGA blend with different compositions showed practically the same peaks as those of pure PE-VOL, although their intensities decreased as the PD,L-LGA in the blend increased. This fact can be explained by the homogeneous distribution of PE-VOL molecules aggregated in the PD,L-LGA matrix; thus, the crystalline aggregates conserve their crystal structures in the PE-VOL/PD,L-LGA blend. The dispersed phase of amorphous polymer acted as a weak nucleating agent. 


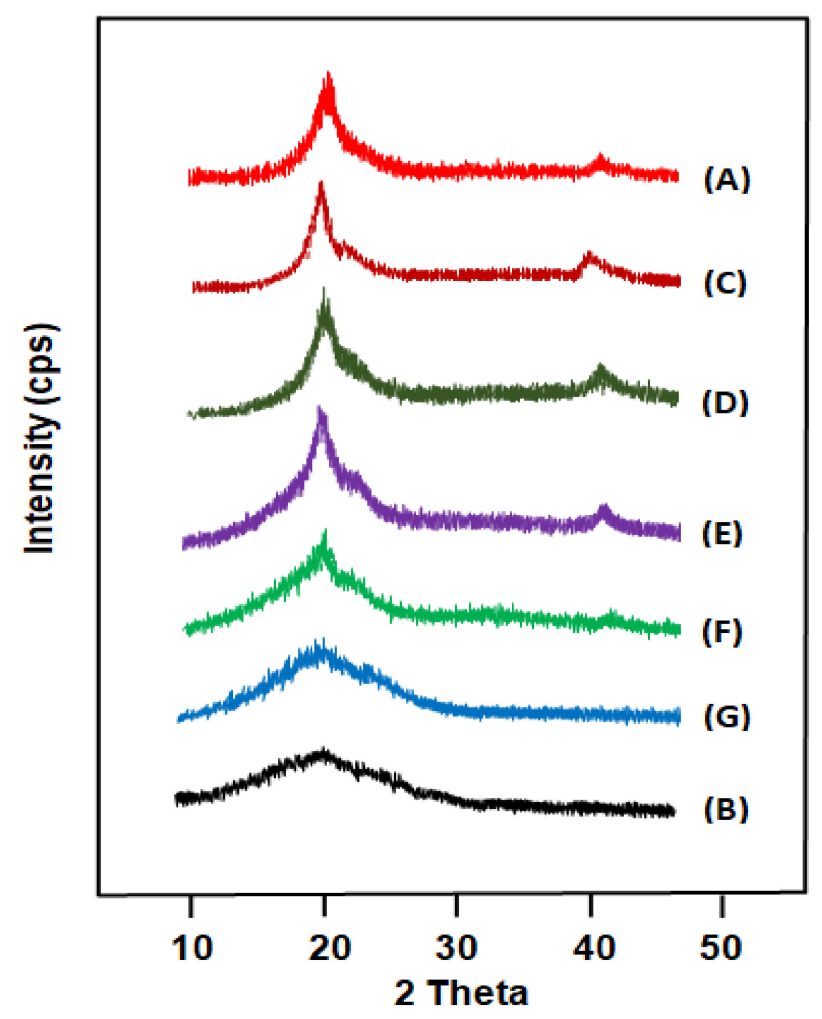

Figure 1. XRD patterns of PE-VOL, PD,L-LGA and PE-VOL/PD,L-LGA blend with different PE-co-VAL contents: (A) neat PE-VOL; (B) neat PD,L-LGA; (C) PE-VOL/PD,L-LGA10; (D) PE-VOL/PD,L-LGA25; (E) PE-VOL/PD,L-LGA50; (F) PE-VOL/PD,L-LGA75; and (G) PE-VOL/PD,L-LGA90.

\subsection{DSC Analysis}

\subsubsection{Miscibility of PE-VOL/PD,L-LGA Blend}

\section{(A) Glass transition temperature}

The heating DSC curves of neat PD,L-LGA, neat PE-VOL and those of their blends with different compositions are presented in Figure 2. As shown in the curve profiles of the blends a confused transition zone is localized between 32 and $60{ }^{\circ} \mathrm{C}$ in which the $T_{g}$ values cannot be localized accurately because of the small difference existing between the $T_{g} \mathrm{~s}$ of the pure components PE-VOL $\left(51^{\circ} \mathrm{C}\right)$ and $\mathrm{PD}, \mathrm{L}-\mathrm{LGA}\left(36^{\circ} \mathrm{C}\right)$ in which this gap does not exceed $15^{\circ} \mathrm{C}$. Consequently, the criterion which stipulates that the miscibility of a pair of polymers can proofed by the presence in the thermogram of the blend of an unique $T_{g}$ cannot be rigorously applied. The same thermograms also show an important depression in the melting temperature of PE-VOL incorporated in the blends with increasing PD,L-LGA content. This finding indicates that the crystalline yield of PE-VOL in the blend dramatically decreased.

Similar results were also observed by different authors using poly(butylene succinate-co-butylene carbonate)/Poly(vinylphenol) blend [47], poly(trimethylene terephthalate)/amorphous poly(ethylene terephthalate) blends [48], and poly(vinylidene fluoride) (PVDF)/poly(methyl methacrylate) (PMMA) blends [49]. This phenomenon may be thermodynamically traduced by the energy of the mixture accompanied by the exothermic interaction energy between the crystalline part of PE-co-VAL and that of the amorphous part of PL-co-GA.

(B) Melting temperature

The DSC thermograms of Figure 2 also show the melting temperatures of the blends and these of their pure components and the data of the apparent melting temperatures and the heat of melting 
deducted are gathered in Table 3. As can be seen from the thermal curves, of the blends only one endothermic peak was observed which is assigned to the apparent melting temperature of the PE-VOL semi-crystalline component. These thermal curves also reveals an important depression of the $T_{m}$ of this semi crystalline copolymer from 188 to $156^{\circ} \mathrm{C}$ when is blended with PD,L-LGA.

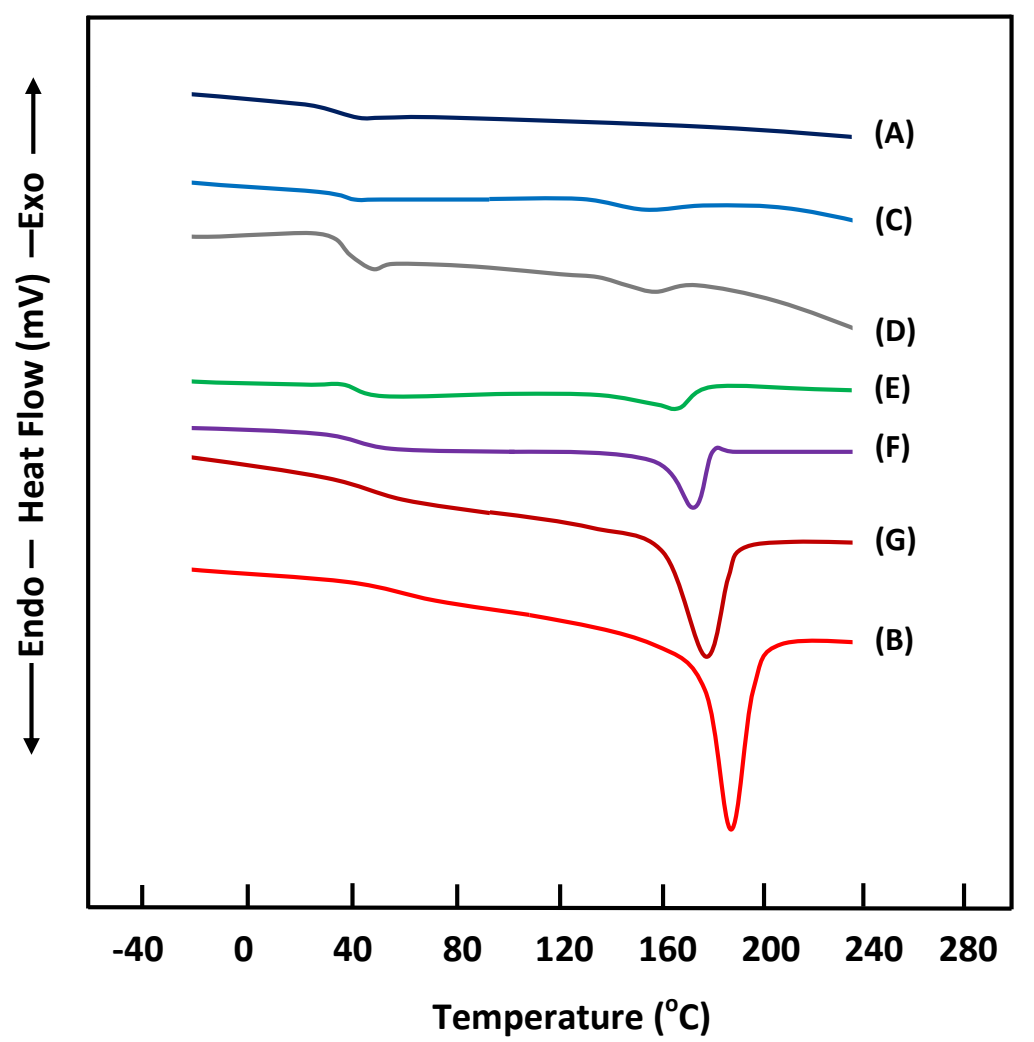

Figure 2. Heating DSC thermograms of copolymers and their blends with different PE-VOH contents: (A) neat PD,L-LGA; (B) neat PE-VOL; (C) PE-VOL/PD,L-LGA10; (D) PE-VOL/PD,L-LGA25; (E) PE-VOL/PD,L-LGA50; (F) PE-VOL/PD,L-LGA75; and (G) PE-VOL/PD,L-LGA90.

Table 3. Comparative data of the glass transition temperatures of copolymers and the apparent melting temperatures of PE-VOL and PD,L-LGA blends with different compositions.

\begin{tabular}{cccc}
\hline System PE-VOL/PD,L-LGA & Volume Fraction, $\boldsymbol{\varphi}_{\mathbf{1}}$ & $\mathbf{T}_{\mathbf{g}}\left({ }^{\circ} \mathbf{C}\right)$ & $\mathbf{T}_{\boldsymbol{m}}\left({ }^{\circ} \mathbf{C}\right)$ \\
\hline $0 / 100$ & 1.00 & 37 & - \\
$10 / 90$ & 0.90 & 38 & 156 \\
$25 / 75$ & 0.75 & 39 & 159 \\
$50 / 50$ & 0.50 & 40 & 165 \\
$75 / 25$ & 0.25 & 41 & 170 \\
$90 / 10$ & 0.10 & 51 & 177 \\
$100 / 0$ & 0.0 & 56 & 188 \\
\hline
\end{tabular}

The decrease of the melting temperature in a semi-crystalline polymer in a miscible blend is due to the thermodynamic interactions between its components. Indeed, the Flory-Huggins theory stipulates that a miscible blend containing a semi crystalline polymer is principally characterized by a depression in its melting temperature permitting the determination of interaction energy. In this same direction, the melting temperature of such polymer is principally affected by different thermodynamic parameters and also by its crystal thickness. In this same way, Hoffman-Weeks method permits the isolation of the morphology parameters from the undesired effects that act on the melting temperature 
of semi-crystalline polymer in its miscible blend using the equilibrium melting temperature, $T_{m}^{o}$, expressed by Equation (3) [50]:

$$
T_{m}=\eta T_{c}+(1-\eta) T_{m}^{o}
$$

The isothermal crystallization process of pure semi-crystalline copolymer and in its blends were realized at different crystallization temperatures, and results obtained for the neat PE-VOL and the PE-VOL/PD,L-LGA containing equal ratio of each component are plotted in Figure 3. Based on the variation of the apparent melting temperature, $T_{m}$, versus the crystallization temperature, $T_{c}$ it was possible to deduct $\eta$ relative to the pure PE-VOL and that in their blends as presented in Figure 4 for the neat PE-VOL and PE-VOL/PD,L-LGA50 system with equal ratios of each component. Indeed, straight lines were obtained and $\eta$ and $T_{m}^{o}$ are deduced from the slope of the Hoffman-Weeks plot and the intercept of these curves with the straight $T m=T_{c}$, respectively. It is important to note that the $\eta$ value varied between zero and the unity. This parameter is used to estimate the stability of molten crystals. Indeed, when the $\eta$ value is close to zero this indicates that the crystals is in its maximum stability and when this parameter is close to one this indicates that this crystals is in its instability state. $T_{m}^{o}$ and $\eta$ values for pure PE-co-VAL and in the blends are listed in Table 4.

As can be seen from these data, the equilibrium melting point of PE-VOL was found to be $184.9^{\circ} \mathrm{C}$, which agrees with that found in literature $\left(187^{\circ} \mathrm{C}\right)[51]$ Concerning the PE- VOL/PD,L-LGA systems, the $T_{m}^{o}$ of the PE-VOL phase decreased with PD,L-LGA content to reach a minimum of $166.8^{\circ} \mathrm{C}$ when the polyester in the blend was $90 \mathrm{wt} \%$. In other terms, the maximum extent of this melting temperature depression was $18.1^{\circ} \mathrm{C}$ when the pure PE-VOL was converted to the PE-VOL/PD,L-LGA10 blend. In general, the $\eta$ values of PE-VOL in its blend, which varied from 0.12 to 0.34 , are relatively small, revealing the stability of pure PE-VOL and PE-VOL in the blend. This parameter decreased slowly with increasing PD,L-LGA content to lose about two-thirds of the crystal stability of PE-VOL when $90 \mathrm{wt} \%$ of the polyester was incorporated. This suggests that the PE-VOL crystals become less and less stable, i.e., they have less thick lamellar thicknesses, when blended with PD,L-LGA. This fact is probably attributed to the morphological effect.

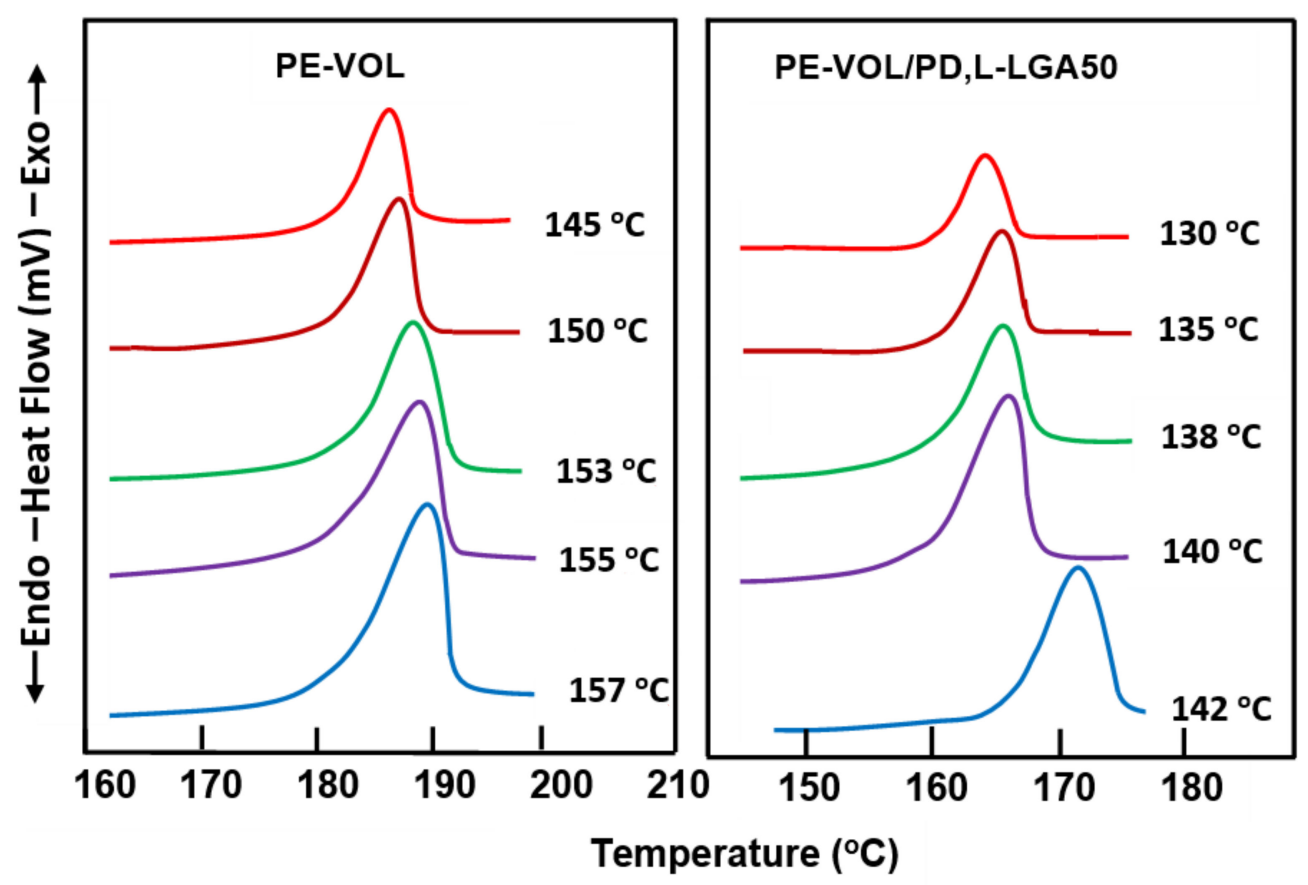

Figure 3. Subsequent melting behaviors of PE-VOL and PE- VOL/PD,L-LGA50 blend isothermally crystallized at the indicated crystallization temperatures. 


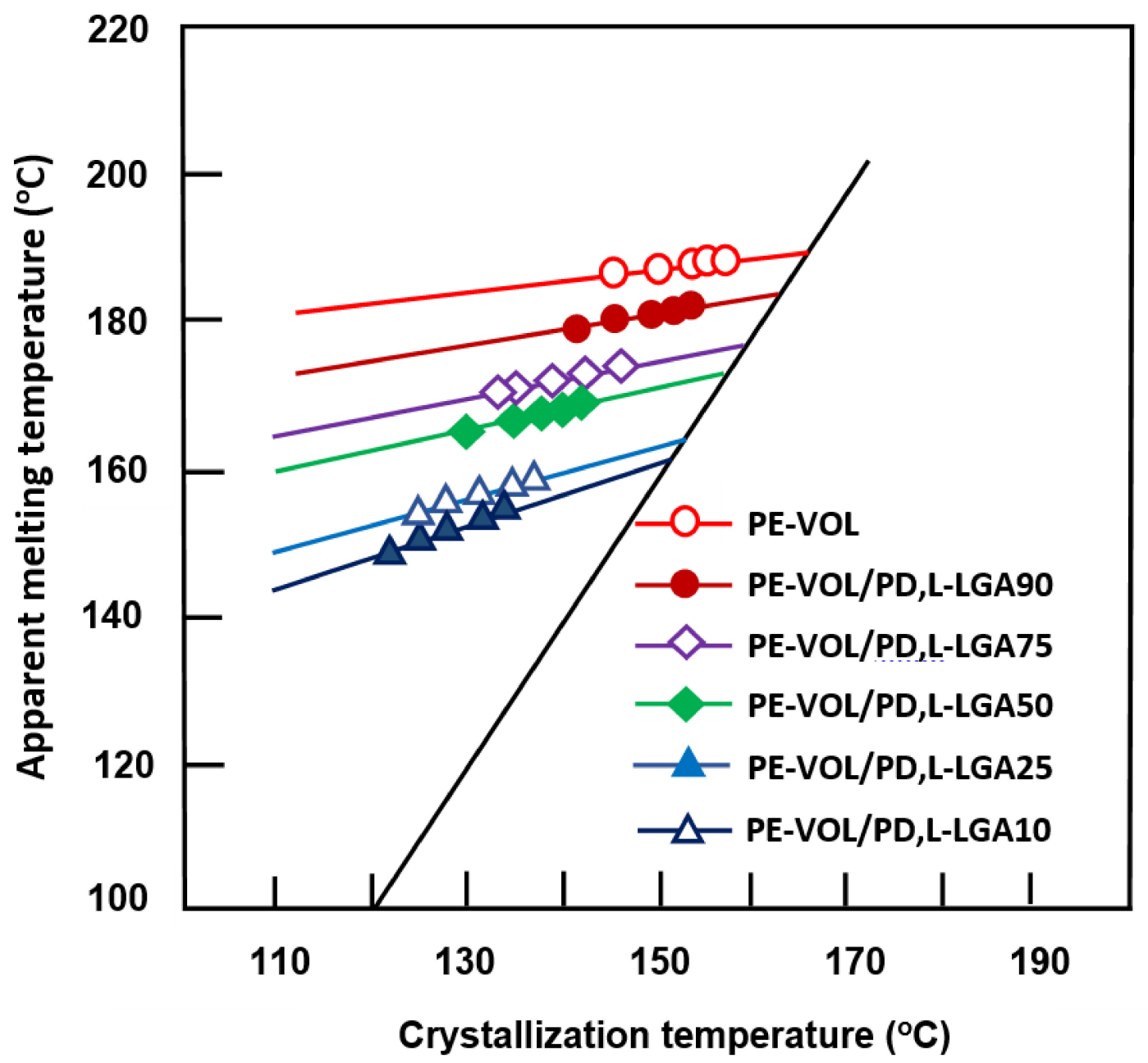

Figure 4. Hoffman-Weeks plots for pure PE-VOL and PE-VOL/PD,L-LGA blend with different PE-VOH contents.

Table 4. Hoffman-Weeks data obtained for PE-VOL/PD,L-LGA blend with different PE-VOH contents.

\begin{tabular}{cccc}
\hline PE-VOL/PD,L-LGA & $\mathbf{T}_{\mathbf{c}}\left({ }^{\circ} \mathbf{C}\right)$ & $\mathbf{T}_{\boldsymbol{m}}^{\boldsymbol{o}}\left({ }^{\circ} \mathbf{C}\right)$ & $\boldsymbol{\eta}$ \\
\hline $100: 0$ & 154 & 184.9 & 0.09 \\
$90: 10$ & 149 & 181.8 & 0.12 \\
$75: 25$ & 143 & 175.5 & 0.18 \\
$50: 50$ & 142 & 171.5 & 0.22 \\
$25: 75$ & 137 & 168.1 & 0.26 \\
$10: 90$ & 135 & 166.8 & 0.34 \\
\hline
\end{tabular}

To rigorously confirm the miscibility of this pair of copolymers, noted by its appearance, it was necessary to use the Flory thermodynamic interaction parameter, $\chi_{1,2}$, determined from the equation of Nishi and Wang, Equation (4) [52], based on the Flory-Huggins theory.

$$
\Delta T_{m}=T_{m}^{o}-T_{m}=-R\left(\frac{V_{u 2}\left(T_{m}^{o}\right)^{2} \chi_{1,2}}{\Delta H_{u 2} V_{u 1}}\right) \varphi_{1}^{2}
$$

where the subscripts 1 and 2 designate the amorphous PD,L-LGA copolymer and the semi crystalline PE-VOL copolymer, respectively. $\varphi_{1}$ is the volume fraction of polymer-1. $V_{u}$ and $\Delta H_{\mathrm{u}}$ are the molar volume and the molar enthalpy of fusion of the repeating units, respectively. $R$ is the gas constant. $\chi_{1,2}$ value is deducted from the slope of the linear curve of Figure 5 , indicating the variation of $\Delta T_{m}$ versus 
the square of $\varphi_{1}$, and the data collected from the literature in which $\Delta \mathrm{H}_{\mathrm{uPE}-\mathrm{VOL}}=4.22 \mathrm{~kJ} \mathrm{~mol}^{-1}$ [53] and $V_{u \text { PE-VOL }}=37.80 \mathrm{~cm}^{3} \mathrm{~mol}^{-1}$ [54] $V_{u \text { PD,L-LGA }}=88.06 \mathrm{~cm}^{3} \mathrm{~mol}^{-1}$ calculated from the density of PD,L-LGA and the molar masses of lactide and glycolic acid co-monomer units. $\chi_{1,2}$ and the interaction energy density between blend components, $\mathrm{B}$, calculated from the $R T_{m}^{o} \chi_{1,2} V_{u 1}^{-1}$ term of Nishi's equation for this pair of polymers are $-0.27 \pm 0.02$ and $-11.67 \pm 0.86$, respectively. The negative sign of these values indicates miscibility in the amorphous part of the PE-VOL/PD,L-LGA system in all investigated compositions. These values are comparable to those created between the ester and hydroxyl groups in the polymer blends such as those investigated by Kuo et al. [55] on the phenolic resin/poly( $\varepsilon$-caprolactone) system, which were $\chi_{1,2}=-0.35$ and $\mathrm{B}=-12.51$. The interaction involved in the miscibility of this blend is principally caused by the hydrogen bonds developed between the carbonyl group of PD,L-LGA and the hydroxyl group of PE- VOL units.

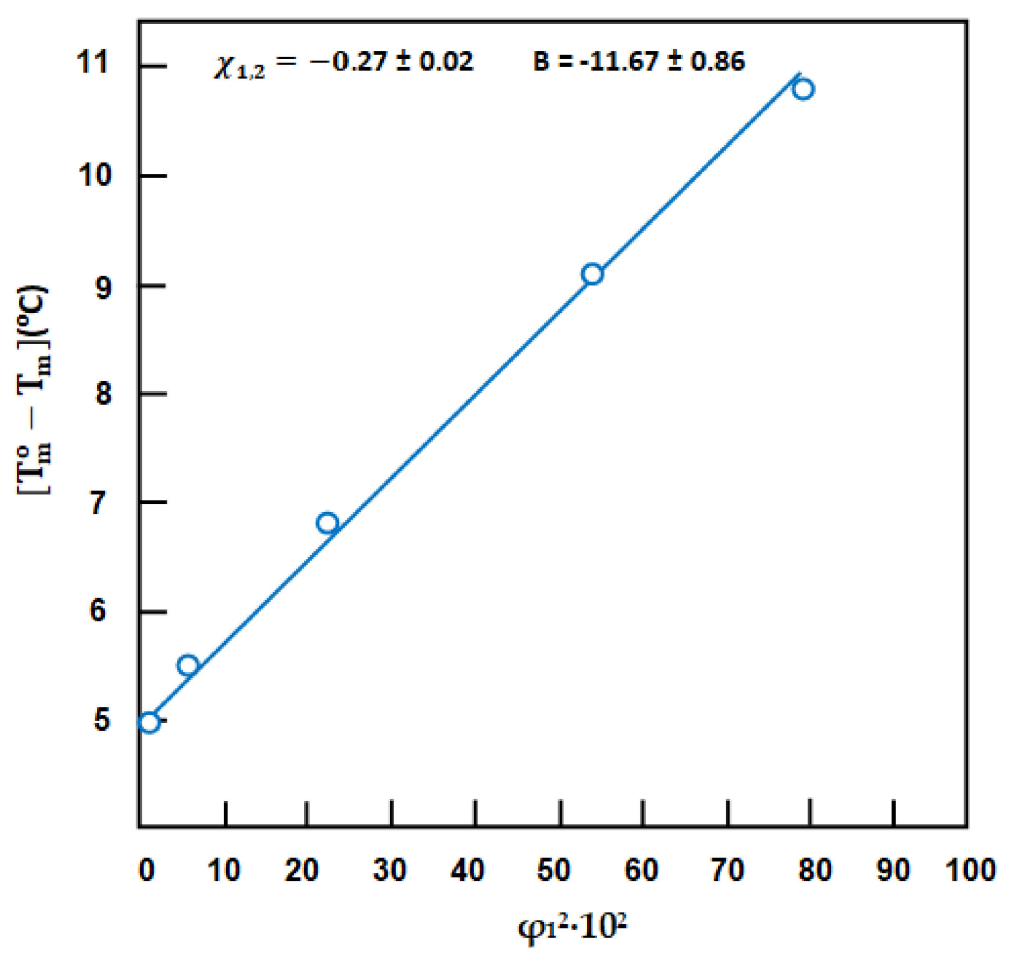

Figure 5. Nishi-Wang curve indicating the variation of $\Delta T_{m}$ versus the square of the PD,L-LGA volume fraction in PE-VOL/PD,L-LGA blends.

\subsubsection{Crystallization Behavior of PE-VOL/PD,L-LGA Blend}

DSC analysis carried out in its cooling mode at different temperatures ranged between $10{ }^{\circ} \mathrm{C}$ and $20^{\circ} \mathrm{C}$ on the neat copolymers and their blends with different compositions led to the thermograms that can be seen in Figure 6. As can be noted from these obtained thermal curve profiles the crystallization temperature, $T_{\mathcal{C}}$, of PE-VOL, taken from the top of the crystalline peaks, depressed with increasing PD,L-LGA content in the blend. As indicated in Table 5, the crystallization enthalpy, $\Delta \mathrm{H}_{\mathrm{C}}$, corresponding to the area of the exothermic peak decreased with increasing the PD,L-LGA content, thus causing an important depression in the crystallinity of PE-VOL in the blend. The incorporation of PD,L-LGA in the PE-VOL matrix makes it difficult to transport the chain segments of this semi-crystalline copolymer towards the crystallization front and, therefore, supercooling is, in this case, necessary for crystallization. Therefore this also limits thickening and perfection of the PE-VOL crystals, thereby causing a depression of the $T_{m}$ and $T_{c}$ values of this copolymer, as shown in Table 4 . In general, the crystallization enthalpy of PE-VOL in the blend shifted toward the low temperature with increasing cooling rate. Similar behavior was also observed in our previous investigations using poly(ethylene-co-vinyl alcohol)/poly(maleic anhydride-alt-ethylene) [56] and by Guo et al. [57] using Poly( $\varepsilon$-caprolactone)/epoxy resin blend. 
According to these authors, the dispersed phase of the amorphous copolymer interacted as a weak nucleating agent.

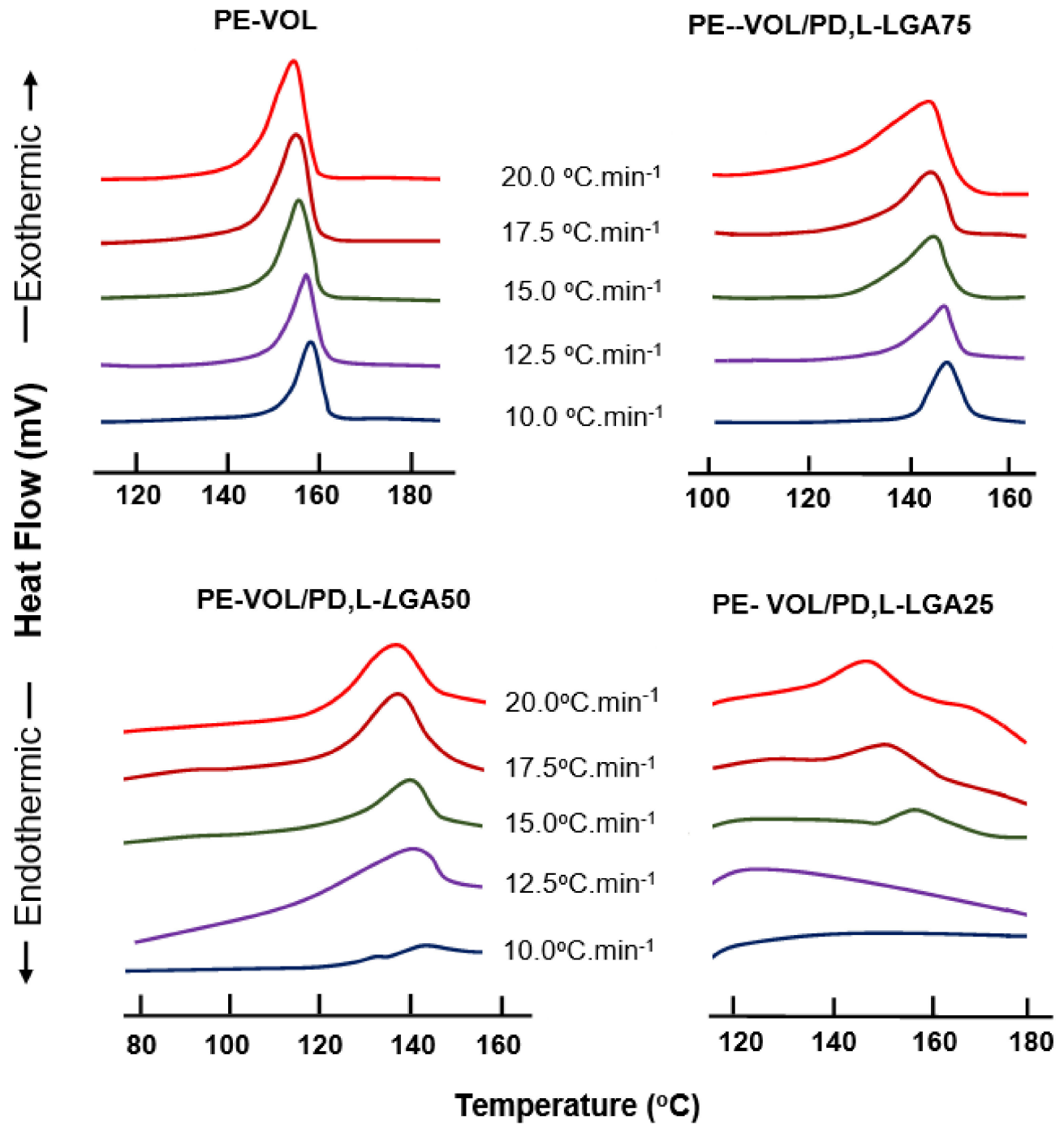

Figure 6. Cooling DSC thermograms of PE-VOL and PE-VOL/PD,L-LGA blends with different compositions and at different cooling rates.

\subsubsection{Non Isothermal Crystallization Kinetics of PE-VOL and PE-VOL/PD,L-LGA Blend}

The determination of the crystallinity degree, $X_{\mathcal{c}}$, is obtained from the latent heat of the crystallization of crystalline polymer in the blend during the crystallization process. This parameter is expressed according to Equation (5) [58]:

$$
X_{c}(\%)=\frac{\Delta H_{c}}{(1-\varphi) \times \Delta H_{m}} \times 100
$$

where $\Delta H_{c}$ represents the apparent latent heat of crystallization of PE-VOL in the blend and $\Delta H_{m}$ the extrapolation of the latent heat corresponding to the melting of PVA 100\% crystalline. Note that the $\Delta H_{m}$ taken from the literature has an average value of $157.8 \mathrm{~J} \cdot \mathrm{g}^{-1}$ [59] $\varphi$ is the mass fraction of the amorphous copolymer (PL-co-GA) incorporated in the blend. The values $X_{c}$ for PE-VOL and PE-VOL/PD,L-LGA blend with different PE-VOH contents obtained from this equation are gathered in Table 4. Figure 7 shows the effect of the dispersion of PD,L-GLA in the blend on the non-isothermal crystallization kinetics of PE-VOL in the blend. As can be seen from these thermal curve profiles, 
the peak of the crystallization enthalpy is lower when the PD,L-LGA content in blend was $10 \mathrm{wt} \%$. On the other hand, as in case of the neat PE-VOL, it was observed that, for all blend compositions, the $T_{c}$ value of PE-VOL slowly shifted toward the lower temperatures as the cooling rate increased. This phenomenon was also revealed by different investigators [60-62] and attributed this fact to a reduction of chain mobility and flexibility limiting the time of diffusion inside the crystalline lattice of the PE-VOL matrix. This fact leads to reduce the crystallization rate of the semi-crystalline copolymer in the blend. Indeed, when the blend samples are cooled down at relatively high cooling rates, the movement of PE-VOL chains do not seem to follow the cooling temperature regime imposed over time due to the influence of thermal hysteresis, which leads to a lower maximum crystallization temperature. When incorporated into the PE-VOL matrices, the macromolecular chains of PD,L-LGA act as an energy barrier preventing heat transfer to the PE-VOL chains. Therefore, at a high PD,L-LGA content in the blend, the crystallization process occurs at a relatively low temperature.

Table 5. Apparent crystallization degree and crystallization enthalpy of pure PE-VOL and PE-VOL in the blend with different compositions and cooling rates.

\begin{tabular}{cccc}
\hline System & $\boldsymbol{\beta}\left({ }^{\circ} \mathbf{C} \mathbf{~ m i n}^{-\mathbf{1}}\right)$ & $\Delta \mathbf{H}_{\mathbf{c}}\left(\mathbf{J} \mathbf{g}^{-\mathbf{1}}\right)$ & $\mathbf{X}(\mathbf{\%})$ \\
\hline \multirow{2}{*}{ PE-VOL } & 10.0 & 46.98 & 29.77 \\
& 12.5 & 47.11 & 30.00 \\
& 15.0 & 56.00 & 35.48 \\
& 17.5 & 54.00 & 34.22 \\
PE-VOL/PD,L-LGA90 & 20.0 & 57.00 & 36.12 \\
\hline & 10.0 & 35.22 & 24.78 \\
PE-VOL/PD,L-LGA75 & 12.5 & 40.17 & 28.78 \\
& 15.0 & 46.03 & 32.41 \\
& 17.5 & 48.86 & 34.44 \\
& 20.0 & 52.47 & 36.95 \\
\hline PE-VOL/PD,L-LGA25 & 10.0 & 27.00 & 22.81 \\
& 12.5 & 30.32 & 25.62 \\
& 15.0 & 32.04 & 27.07 \\
& 17.5 & 36.57 & 30.90 \\
& 20.0 & 41.21 & 34.82 \\
\hline & 10.0 & 13.36 & 16.93 \\
& 12.5 & 17.46 & 22.13 \\
& 15.0 & 21.2 & 24.12 \\
& 17.5 & 25.81 & 32.71 \\
& 20.0 & 28.19 & 35.73 \\
\hline & 10.0 & - & - \\
& 12.5 & 2.18 & 10.95 \\
& 20.0 & 4.32 & 15.51 \\
\hline
\end{tabular}

The degree of relative crystallinity, $X_{T}$, of PE-VOL in the blend versus temperature is given by Equation (6) [63]:

$$
X_{T}=\frac{\int_{T_{o}}^{T}\left(\frac{d H}{d T}\right) d T}{\int_{T_{o}}^{T_{\infty}}\left(\frac{d H}{d T}\right) d T}
$$

where $T_{o}$ and $T_{\infty}$ are the beginning and finishing crystallization temperatures measured at the starting and finishing inflections of the crystallization peaks, respectively. $H$ is the heat of the crystallization process of neat PE-VOL or PE-VOL in the blend at temperature, $T$. $X_{T}$ can be determined after replacing 
integrations functions by the areas under the DSC crystallization peaks in the DSC thermograms from $T=T_{o}$ to $T=T\left(A_{T}\right)$ and the area under the total crystallization peak $\left(A_{T}\right)$, Equation (6) becomes:

$$
X_{T}=\frac{A_{T}}{A_{\infty}}
$$

The variation of the relative crystallization time, $X_{t}$ is calculated from the temperature $T$ at crystallization time $t$ and the cooling rate $\beta$ according Equation (8):

$$
t=\frac{\left(T_{o}-T\right)}{\beta}
$$

Typical plots of the variation of the relative crystallization degree of neat PE-VOL and PE- VOL in the blend as function of temperature, $X_{T}$, and time, $X_{t}$, are obtained during the non isothermal crystallization process and the curves of pure PE-VOL and PD,L-LGA/PE-VOL50 taken as examples are presented in Figure 8A,B, respectively. Sigmoid pattern was obtained for each sample and the rate of the crystallization deducted from the slope is almost constant between $20 \%$ and $80 \%$ of the relative crystallinity and due to the spherulite impingement effect, these curve profiles tend to become flat beyond [58].

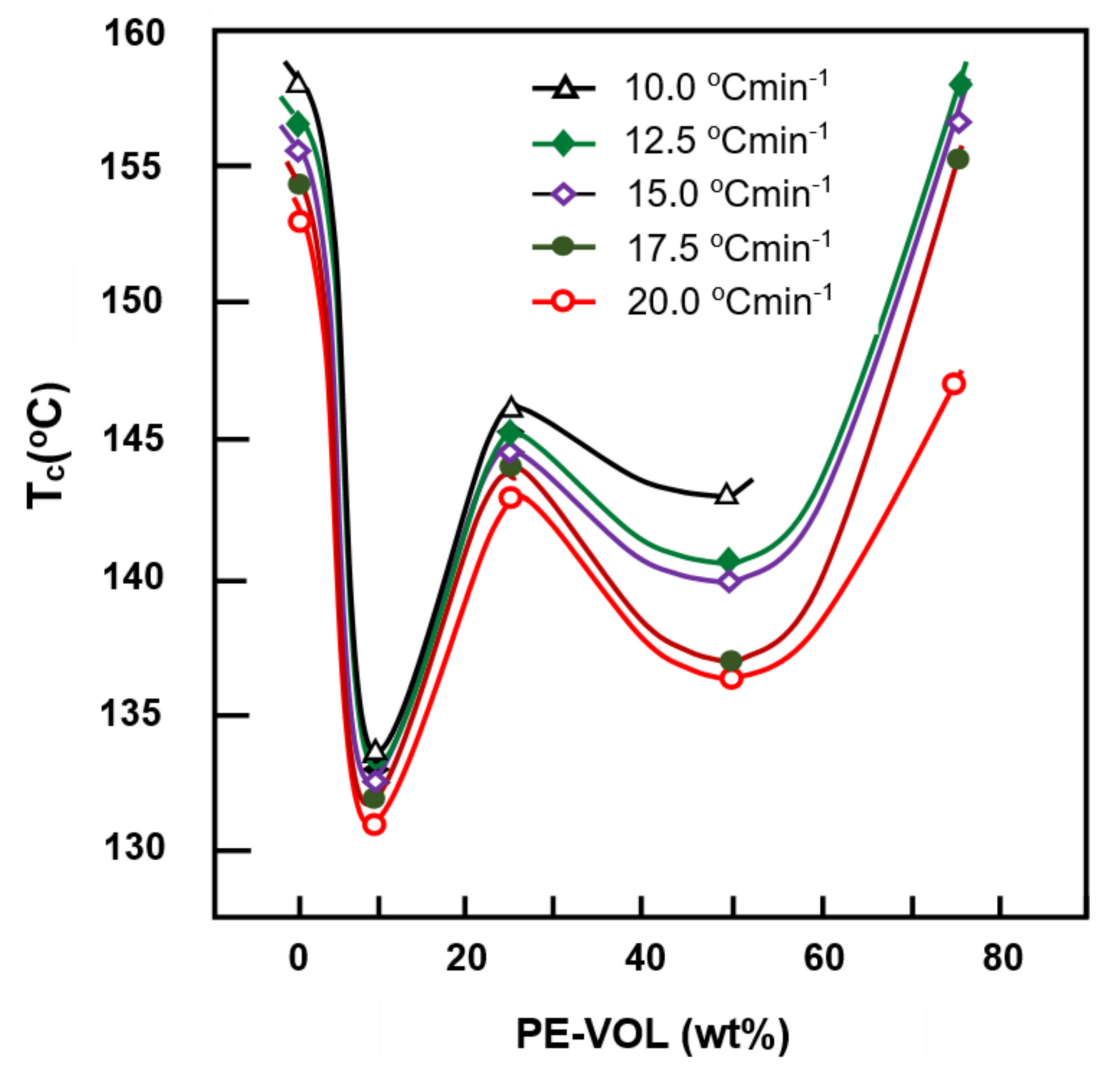

Figure 7. Variation of the crystallization temperature of the PE-VOL in the blend versus the PE-VOL content at different cooling rates. 

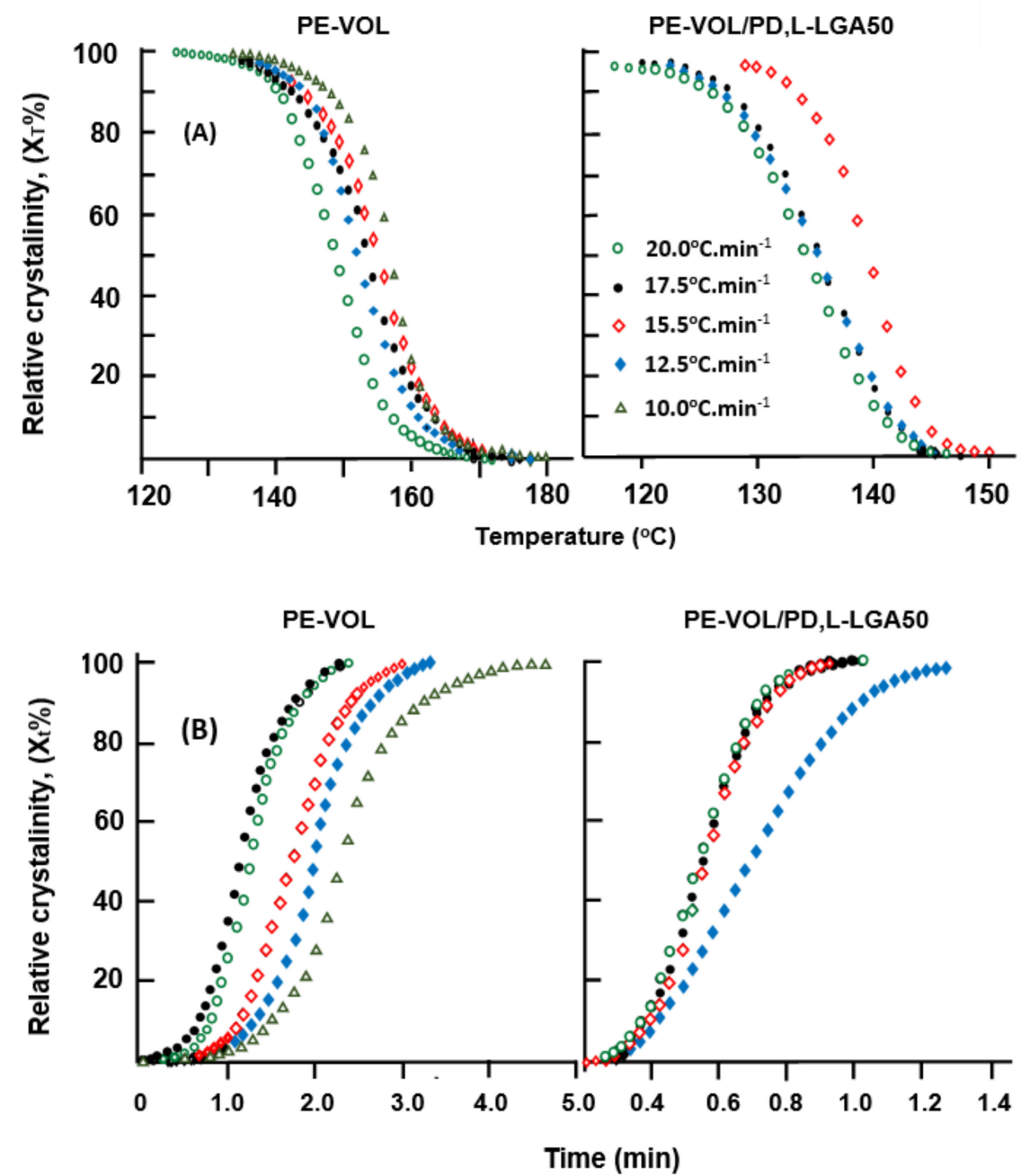

Figure 8. Variation of the relative crystallinity of pure PE-VOL and PE-VOL/ PD,L-LGA50 blend with temperature (A) and time (B) for various cold crystallization temperatures.

The half time, $t_{1 / 2}$, of the crystallization process was deducted from the curves of Figure $8 \mathrm{~B}$ at $50 \%$ of the relative crystallization of pure PE-VOL and PD,L-LGA/PE-VOL systems and the data obtained are plotted in Figure 9. For the pure PE-VOL, in general these curve profiles reveal an increase in the $t_{1 / 2}$ with increasing the cooling rate. On the other hand, when the PD,L-LGA was incorporated in the PE-VOL matrix the $t_{1 / 2}$ passed by a minimum at $30 \mathrm{wt} \%$ of this amorphous copolymer in the blend. Indeed, the crystallization process of PE-VOL in the blend was dramatically decelerated when the PD,L-LGA content was $30 \%$, in which the $t_{1 / 2}$ loses $45 \%-83 \%$ of its value depending on the cooling rate. This observation can be explained by the fact that at a relatively low PD,L-LGA content, the macromolecular chains of this last copolymer cluster cannot restrict the motion of the PE-VOL macromolecular chains but act as heterogeneous nucleating agents during the non-isothermal crystallization process and therefore accelerate the crystallization. At a higher PD,L-LGA content, the macromolecular chains of PD,L-LGA clusters act as a barrier that restricts the thermal motion of PE-VOL macromolecular chains and therefore retards the formation of crystals. As a result, the addition of a large amount of PD,L-LGA can delay the overall crystallization process. 


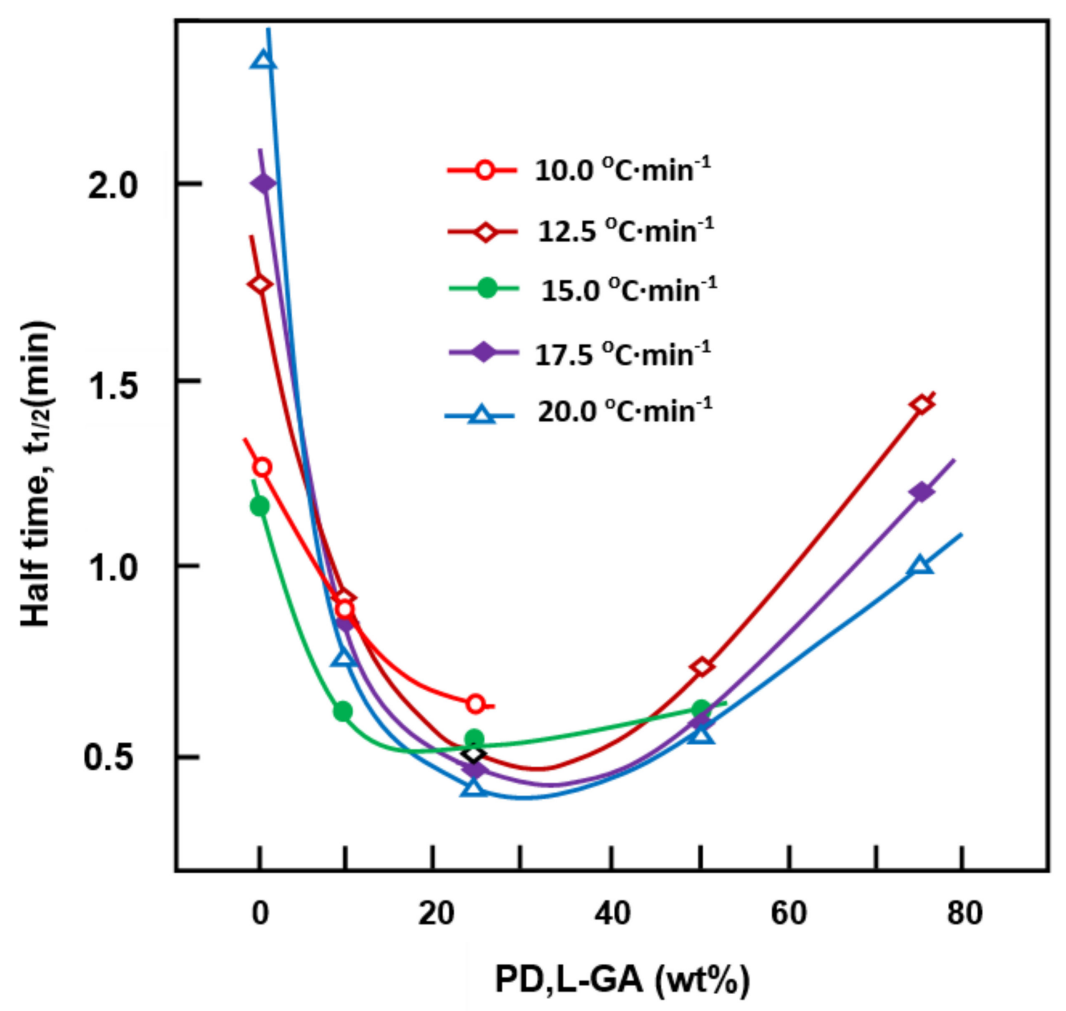

Figure 9. Variation of the half time versus the PD,L-LGA content incorporated in the PE-VOL matrix.

Among many models that have been developed to investigate the non-isothermal ctystallization kinetics [64-67] the Ozawa Equation (9) extended from that given by Avrami Equation (10) [68] is adopted in this work to study the non-isothermal crystallization kinetics of the PE-VOL/PD,L-LGA blend and its pure semi-crystalline component.

$$
\begin{aligned}
& 1-X_{T}=\exp \left(-\frac{k_{T}}{\beta^{m}}\right) \\
& 1-X_{t}=\exp \left(-k t^{n}\right)
\end{aligned}
$$

The Avrami equation originally applied for isothermal crystallization is also applied for non-isothermal crystallization by assuming that the specimen is cooled at a constant cooling rate. Note that $X_{t}$ and $X_{T}$ represent the relative degrees of crystallinity at time $(t)$ and temperature $(T)$, respectively, $k$ and $k_{T}$ are the crystallization kinetics rate constant and the cooling function of non-isothermal crystallization at temperature (T), respectively, $\beta$ is the cooling rate, and $n$ and $m$ are the isothermal Avrami and the Ozawa exponents depending on the dimension of crystal growth and nucleation mechanism, respectively. Equation (10) can be linearized as follows:

$$
\ln \left[-\ln \left(1-X_{T}\right)\right]=\ln k_{T}-m \ln \beta
$$

As can be seen from the plots of $\ln [-\ln (1-X t)]$ versus $\ln (\beta)$ for PE-VOL and PE-VOL/PD,L-LGA systems in Figure 10, all specimens containing different PD,L-LGA contents showed straight lines indicating that the Ozawa equation Equation (8) described the primary process of non-isothermal crystallization of pure PE-VOL and its blends perfectly. The values of $k_{\mathrm{T}}$ and $m$ deduced from the intercept and slope of these curves, respectively, are gathered in Table 6. As can be seen from these data, the value of $m$ for pure PE-VOL increased from 1.24 to 1.55 with the crystallization temperature, which agrees with the results of the literature [69]; however, the values of $m$ for the blends, in general, are opposite that of pure PE-VOL and randomly fluctuated between 1.55 and 3.60 depending on the 
temperature and PE-VOL/PD,L-LGA composition, suggesting that the introduction of PD,L-LGA content in the PE-VOL matrix does not significantly influence the growth of crystals. In certain cases of PE- VOL/PD,L-LGA systems, the small increase of $m$ observed when the temperature increased reveals a small change in the crystallization mechanism, probably due to the decrease in the viscosity of blend caused by a rupture of the strong interactions between hydroxyl groups of PE-VOL chains for the profit of the weak interactions between hydroxyl of PE-VOL and carbonyl of PD,L-LGA. The increasing $m$ values are usually attributed to the change from instantaneous to sporadic nucleation [70] According to typical polymer crystallization reports, an $m$ value of 2 indicates that the crystal growth is sporadic and spherical and occurs from nuclei. Heterogeneous nucleation has been suggested for fractional $m$ values in polymer crystallization [71] The $k_{T}$ value related to the all over crystallization rate decreased when the temperature decreased, except in the blend with $25 \%$ of PD,L-LGA content in which this parameter increased. This means for PE-VOL and PE- VOL/PD,L-LGA blends with PD,L-LGA content inferior to $25 \mathrm{wt} \%$, the crystallization rate increased when the temperature decreased, especially in the case of pure PE-VOL, in which this parameter dramatically decreased. In addition, $k_{T}$ values depend on the PE-VOL/PD,L-LGA composition.

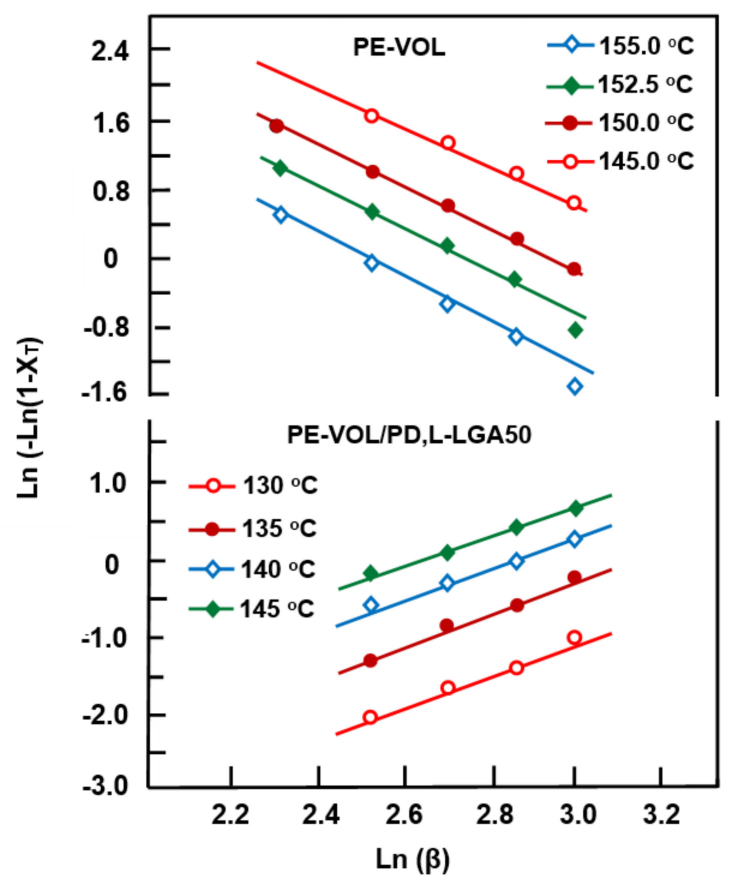

Figure 10. Ozawa plots of $\operatorname{Ln}\left[-\operatorname{Ln}\left(1-X_{T}\right)\right]$ versus $-\operatorname{Ln}(\beta)$ for pure PE-VOL and PE-VOL/PD,L-LGA50.

The crystallization activation energy $\left(E_{c}\right)$ associated with the overall crystallization process is evaluated from the rates of crystallization using the Kissinger Equation (12) [72]:

$$
E_{c}=\frac{\mathrm{d}\left[\ln \left(\beta / T_{c}^{2}\right)\right.}{\mathrm{d}\left(1 / T_{p}\right)} R
$$

where $R$ and $T_{c}$ are the gas constant and the peak crystallization temperature, respectively. $E_{c}$ is obtained from the slope of the plots $R \ln \left(\beta / T_{c}{ }^{2}\right)$ versus 1/T of Figure 11. The curve (on the top) indicating the variation of the crystallization activation energy versus the PE-VOL content showed that the $E_{c}$ passed by a maximum at $337 \pm 12 \mathrm{Kj}$ when the PE-VOL content in the blend was $75 \mathrm{wt} \%$. The increase in $E_{c}$ can be explained by the increase in the miscibility of PE-VOL/PD,L-LGA system because increasing the PD,L-LGA in the blend results in dilution of PE-VOL chains at the crystal growth front and 
contributes to the reduction of mobility of PD,L-LGA chains due to the higher $T_{g}$ of the blend than that of pure PE-VOL, thus a higher value for PE-VOL crystallization occurs in the blends.

Table 6. Ozawa parameter $(m)$ and cooling function $\left(k_{T}\right)$ for pure PE-VOL and PE-VOL in the blend with different compositions.

\begin{tabular}{|c|c|c|c|c|}
\hline System & $\begin{array}{l}\text { PE-VOL/PD,L-LGA } \\
\text { Composition (wt \%) }\end{array}$ & $\mathrm{T}\left({ }^{\circ} \mathrm{C}\right)$ & $\mathbf{m}$ & $\mathbf{k}_{\mathbf{T}}$ \\
\hline \multirow{4}{*}{ PE-VOL } & \multirow{4}{*}{$100 / 0$} & 145 & 1.30 & 85.62 \\
\hline & & 150 & 1.60 & 112.17 \\
\hline & & 152.5 & 1.94 & 172.43 \\
\hline & & 155 & 2.40 & 1299.80 \\
\hline \multirow{4}{*}{ PE-VOL/PD,L-LGA90 } & \multirow{4}{*}{$90: 10: 00$} & 130 & 2.70 & 340.36 \\
\hline & & 135 & 2.40 & 107.77 \\
\hline & & 140 & 2.24 & 30.88 \\
\hline & & 145 & 2.80 & 33.11 \\
\hline \multirow{4}{*}{ PE-VOL/PD,L-LGA75 } & \multirow{4}{*}{$75: 25: 00$} & 130 & 1.70 & 235.10 \\
\hline & & 135 & 1.90 & 190.57 \\
\hline & & 140 & 2.00 & 167.33 \\
\hline & & 145 & 2.32 & 138.38 \\
\hline \multirow{4}{*}{ PE-VOL/PD,L-LGA50 } & \multirow{4}{*}{ 50:50:00 } & 130 & 2.00 & 115.58 \\
\hline & & 135 & 2.10 & 76.69 \\
\hline & & 140 & 2.00 & 46.99 \\
\hline & & 145 & 2.00 & 18.73 \\
\hline \multirow{4}{*}{ PE-VOL/PD,L-LGA25 } & \multirow{4}{*}{$25: 75$} & 130 & 1.40 & 51.94 \\
\hline & & 135 & 1.64 & 60.34 \\
\hline & & 140 & 2.00 & 86.49 \\
\hline & & 145 & 2.60 & 170.72 \\
\hline
\end{tabular}

\subsection{TGA Analysis}

The thermal stabilities of the pure PE-VOL and PD,L-LGA and the PE-VOL/PD,L-LGA blend investigated by the TGA method are shown in the thermograms of Figure 12. One, two, and three principal decomposition stages were observed for PD,L-LGA, PE-VOL, and blends, respectively. The thermal decomposition of PE-VOL and PD,L-LGA starts at 350 and $270{ }^{\circ} \mathrm{C}$, respectively, indicating that the first copolymer is much more stable than the second. Similar values were also reported by Alvarez et al. [73] for PE-VOL and Park et al. [74] for PD,L- LGA. According to Alvarez et al., the decomposition of PE-VOL overlaps those of both poly(vinylalcohol) and poly(ethylene) under the same conditions. These authors reported that the thermal degradation of this copolymer at temperature ranged between $350^{\circ} \mathrm{C}$ and $412{ }^{\circ} \mathrm{C}$ is essentially due to the decomposition of the alcoholic sequences. According to Holland et al. [75], the resulting products from the thermal decomposition of PVA, in this temperature range, lead to water elimination and chain scission through a six-membered transition state, leading principally to the formation of volatile product, such as aldehydes and ketones. When the temperature increased to higher than $412{ }^{\circ} \mathrm{C}$, the decomposition of co-component PE occurs, leading to a release of ethylene and other volatile hydrocarbon compounds. According to Sivalingam et al. [76], the decomposition of PD,L-LGA involves a random chain scission at the beginning of the degradation process and then a specific chain scission at the end. At a lower temperature, the decomposition of PD,L-LGA follows the main degradation mechanism which is inspired from the mechanism of PLG and PLA involving transposition reactions of non-radical esters of the backbiting type incorporating the hydroxyl group at the end of the chain. This process leads mainly to the formation of linear and cyclic oligomers and to the regeneration of monomers and other products such as acetaldehyde and methylglycolate. Carbon dioxide is also a decomposition product formed by the decarboxylation reactions of the terminal carboxyl groups of the polymer chains [77] At higher 
temperatures, ketene (for PGA), methylketene (for PLA), formaldehyde, and carbon monoxide are also formed via the radical chain scission mechanism [78] Hence, the decomposition of PD,L-LGA forms products similar to neat PLA and PGA homopolymers. Indeed, the decomposition of PD,L-LGA leads to the formation of products similar to the compounds resulting from the process of decomposition of the corresponding homopolymers.

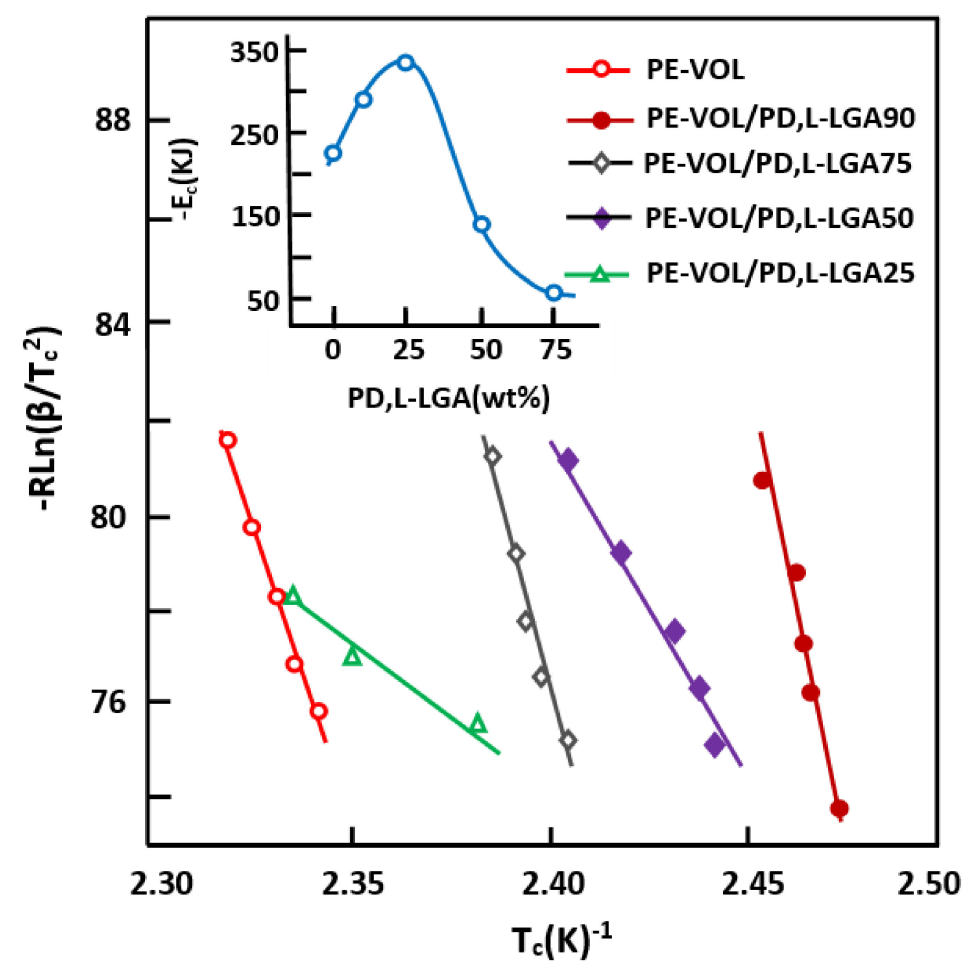

Figure 11. Variation of the $\operatorname{RTLn}\left(\beta \cdot \mathrm{T}_{\mathrm{p}}{ }^{2}\right)$ versus the reverse of crystallization temperature for pure PE-VOL and PE-VOL/PD,L-LGA blend with different compositions. Variation of the crystallization activation energy of PE-VOL/PD,L-LGA blend versus the PD,L-LGA content (in the top).

The TGA thermograms of PE-VOL/PD,L-LGA blends revealed the start of the first decomposition zone at $260^{\circ} \mathrm{C}$ for the blend containing $10 \mathrm{wt} \%$ which then increased with the PE-VOL content in the blend to reach $290{ }^{\circ} \mathrm{C}$ when the blend was PE-VOL/PD,L-LGA90. This temperature is largely superior to that of pure PD,L-LGA $\left(225^{\circ} \mathrm{C}\right)$. As a result of these data, only $10 \mathrm{wt} \%$ of PE-VOL in the blend led to an increase in the thermal stability of PD,L-LGA by $35^{\circ} \mathrm{C}$. In this step, the resulting products were principally attributed to the decomposition of PD,L-LGA component. The compounds yielded from this process are principally cyclic and linear oligomers, monomers, acetaldehyde, ethylglycolate, and carbon dioxide. The second decomposition zone starts at $335^{\circ} \mathrm{C}$ for the PE-VOL/PD,L-LGA10 and increased as the PE-VOL content in the blend increased to reach $365{ }^{\circ} \mathrm{C}$ for the blend containing $90 \mathrm{wt} \%$ of PE-VOL. The principal compounds released during this step are practically the same as those released during decomposition of pure PD,L-LGA. The third zone which starts at $375-420^{\circ} \mathrm{C}$ depending on the PD,L-LGA content in the copolymer coincides with the beginning of the second decomposition zone of the PE-VOL and ends at the same end temperature $\left(\sim 500^{\circ} \mathrm{C}\right)$. During this step, 7-36 wt \% of residue was observed depending on the PD,L-LGA content in the blend. This residue is probably composed of carbon dioxide, ethylene, and other hydrocarbons (saturated and unsaturated). 


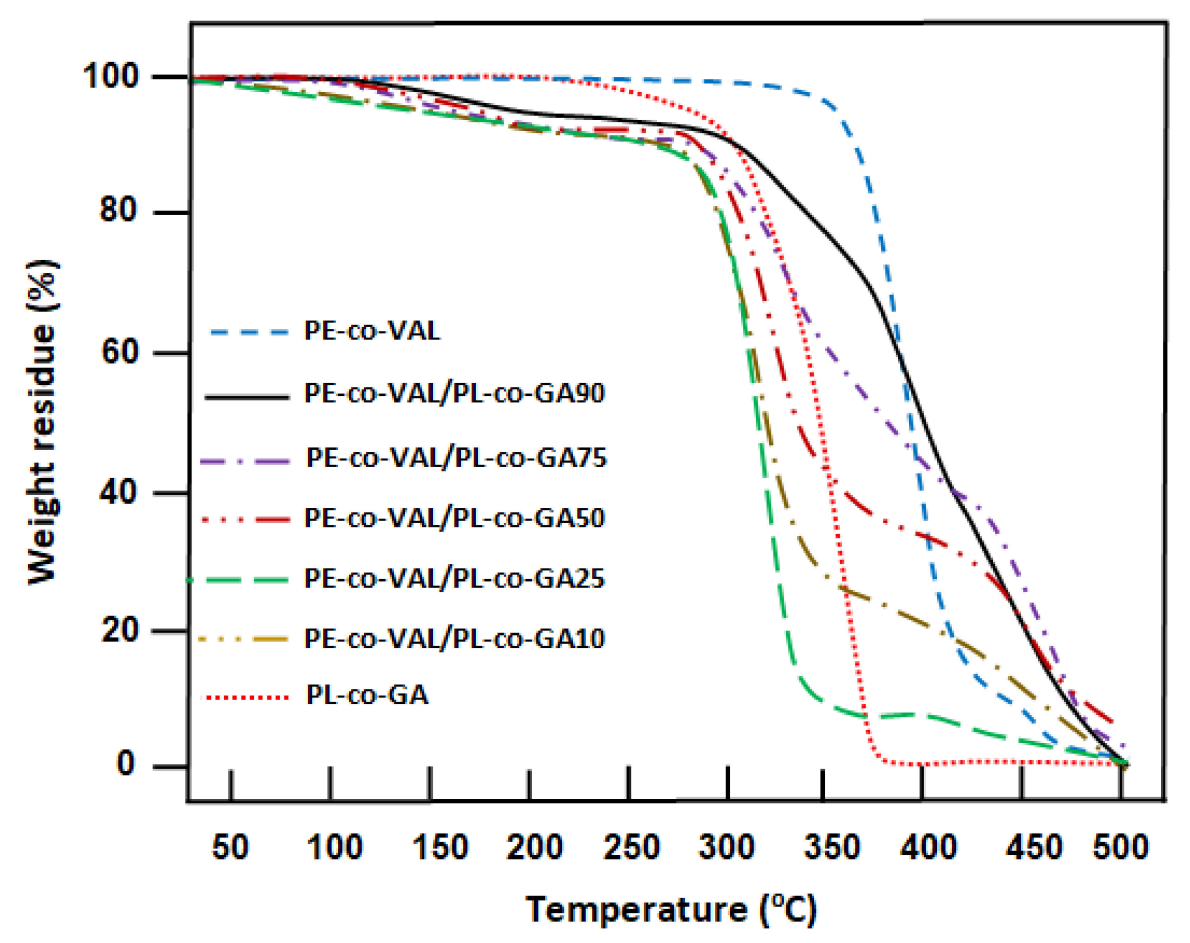

Figure 12. Thermograms TGA of pure PE-VOL, PD,L-LGA and their blends with different compositions.

\subsection{DART-ToF-MS Analysis}

The principal fragments resulting from the isothermal decomposition of PE-VOL, PD,L-LGA and PE-VOL/PD,L-LGA50 blend carried out by DART-ToF-MS analysis at $350{ }^{\circ} \mathrm{C}$, selected from the previous TGA analysis as temperature where pure components and blends decompose, are illustrated in Figure 13. The predominant fragments regenerated from the decomposition of the neat PD,L-LGA were the isomers of $\mathrm{C}_{6} \mathrm{H}_{12} \mathrm{O}_{2}$, glycolic acid monomer $\left(\mathrm{C}_{2} \mathrm{H}_{4} \mathrm{O}\right)$, lactide dimer $\left(\mathrm{C}_{6} \mathrm{H}_{8} \mathrm{O}_{4}\right)$ and the isomers of $\mathrm{C}_{11} \mathrm{H}_{16} \mathrm{O}_{9}$ formed from fragmentation of polymeric chains followed by a rearrangement and transposition through a complex radical mechanism. On the other hand, the decomposition of neat PE-co-VOH led to the production of a significant amount of $\mathrm{C}_{12} \mathrm{H}_{15} \mathrm{O}_{2}$ containing several conjugated double bonds resulting from the water elimination of this copolymer. In contrast, the spectrum of the decomposition involving the two copolymers in the blend is completely different. Indeed, the comparison of the spectrum visualizing the resulting fragments of the decomposition of the blend with those of the neat components reveals no signals common attributed to those observed in the spectra of the two pure components. This result is probably due to inter-transposition of radical groups from one chain to another neighboring chain of different natures. Such phenomenon is generally favored in certain conditions such as the miscibility of the blend, decomposition temperature, and interaction forces between the different polymer chains such as hydrogen bonding (carbonyl-hydroxyl groups). This action can only be possible when the two different copolymers are distributed in the matrix of one in the other +on their molecular scale. This finding may provide additional evidence confirming the miscibility of this blend. Indeed, the DART-ToF-MS spectrum of the PD,L-LGA/PE-VOL50 blend shows a series of chain fragments in which the principal components are aliphatic and aromatic isomers of $\mathrm{C}_{10} \mathrm{H}_{16} \mathrm{O}_{2}, \mathrm{C}_{8} \mathrm{H}_{19} \mathrm{O}_{5}, \mathrm{C}_{7} \mathrm{H}_{16} \mathrm{O}_{7}, \mathrm{C}_{14} \mathrm{H}_{24} \mathrm{O}_{4}, \mathrm{C}_{16} \mathrm{H}_{18} \mathrm{O}_{5}, \mathrm{C}_{10} \mathrm{H}_{16} \mathrm{O}_{2}$, and $\mathrm{C}_{12} \mathrm{H}_{27} \mathrm{O}_{7}$. Small molecules resulted from elimination reactions such as water and $\mathrm{CO}_{2}$ were also produced, which do not appear on this spectrum. However, neither the monomer nor dimer and oligomers are among the decomposition products of the blend. 

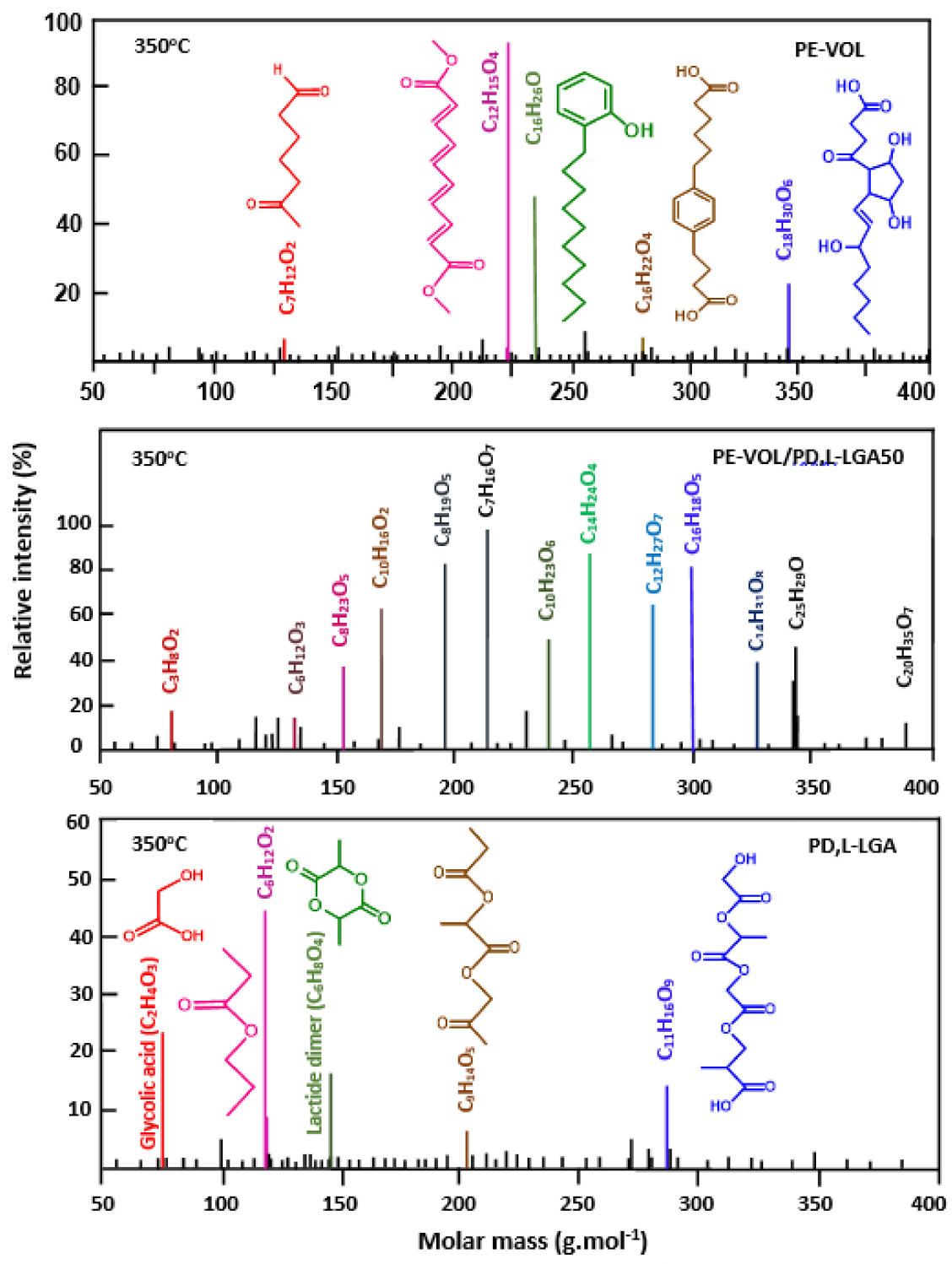

Figure 13. DART-Tof-MS spectra of the isothermal decomposition of PE-VOL, PD,L-LGA and PE-VOL/PD,L-LGA50 blend indicating the relative ion intensity signals of the resulting products versus their molecular weights.

\section{Conclusions}

The PE-VOL/PD,L-LGA blend was proved miscible in all composition investigated by viscosimetry method through the positive values of the viscosity parameter, $\alpha$, determined by the San et al. equation. This finding was confirmed by the DSC method through the presence of negative values of intermolecular interaction parameter, $\chi_{1,2}$, determined from the Nishi equation and the reduction of different thermodynamic and crystallographic parameters with the PD,L-LGA content. The non-isothermal crystallization kinetics carried out on the PD,L-LGA/PE-VOL blend system and its semi-crystalline component, PE-VOL, revealed that the Ozawa approach described the primary crystallization process of this pure copolymer alone and when blended with this amorphous PD,L-LGA copolymer. The $m$ values resulted for the blend systems were comparable to those of the neat copolymer, thus suggesting that the incorporation of PD,L-LGA in the PE-VOL matrix did not significantly influence the crystal growth. The $\mathrm{E}_{\mathrm{c}}$ of the pure PE-VOL and blends determined by Kissinger relationship revealed activation energies superior to that of neat PE-VOL. This result indicates that the polymeric chains of the PD,L-LGA amorphous component act as heterogeneous nuclei and accelerate the dynamic 
of the non-isothermal crystallization process. In contrast, at lower PD,L-LGA contents, the chains of this copolymer clusters act as a barrier to retard the dynamic of the non-crystallization process through a depression of the crystal growth. The X-RD analysis revealed that the PE-VOL was homogeny distributed in its aggregate form into the PE-VOL/PD,L-LGA blend, thus preserving its crystal system. The TGA thermograms of the PE-VOL/PD,L-LGA blends and those of their pure components revealed a significant improvement in the thermal stability of the PD,L-LGA in which only $10 \%$ by weight of PE-VOL was sufficient to improve its thermal stability by $35{ }^{\circ} \mathrm{C}$. The isothermal decomposition of neat copolymers and their blends carried out by the DART-ToF-MS method revealed that the fragmentation of PE-VOL at $350^{\circ} \mathrm{C}$ are principally isomers of $\mathrm{C}_{7} \mathrm{H}_{12} \mathrm{O}_{2}, \mathrm{C}_{12} \mathrm{H}_{15} \mathrm{O}_{4}, \mathrm{C}_{16} \mathrm{H}_{26} \mathrm{O}, \mathrm{C}_{16} \mathrm{H}_{22} \mathrm{O}_{4}$, and $\mathrm{C}_{18} \mathrm{H}_{30} \mathrm{O}_{6}$, whereas for the PD,L-LGA at this same temperature, the decomposition process leads to the regeneration of the starting monomer, dimer, and oligomers and large amounts of isomers of $\mathrm{C}_{9} \mathrm{H}_{14} \mathrm{O}_{5}$ and $\mathrm{C}_{11} \mathrm{H}_{16} \mathrm{O}_{9}$. The isothermal decomposition of copolymers and their blends by the DART-ToF-MS method reveal that the products resulted from the fragmentation of PE-VOL at $350{ }^{\circ} \mathrm{C}$ are principally the isomers of $\mathrm{C}_{7} \mathrm{H}_{12} \mathrm{O}_{2}, \mathrm{C}_{12} \mathrm{H}_{15} \mathrm{O}_{4}, \mathrm{C}_{16} \mathrm{H}_{26} \mathrm{O}, \mathrm{C}_{16} \mathrm{H}_{22} \mathrm{O} 4$ and $\mathrm{C}_{11} \mathrm{H}_{16} \mathrm{O}_{9}$, while for the $\mathrm{PD}, \mathrm{L}-\mathrm{LGA}$ at $350{ }^{\circ} \mathrm{C}$ the decomposition process leads to the regeneration of the starting monomer, dimer, oligomers and huge amounts of isomers of $\mathrm{C}_{9} \mathrm{H}_{14} \mathrm{O}_{5}$ and $\mathrm{C}_{11} \mathrm{H}_{16} \mathrm{O}_{9}$. In contrast, the process of decomposition of the blend engenders the formation of new products different from those of the two copolymers, caused by inter-transposition of radical groups from one chain to another neighboring chain of different nature. Indeed, this action can only be possible when the two different copolymers are distributed in the matrix of one in the other on their molecular scale. This finding may be additional evidence that confirms the miscibility of this blend.

Author Contributions: Data curation, A.-B.A.-O.; Formal analysis, M.O., W.S.S., A.-B.A.-O., A.Y.B.H.A. and T.A.; Funding acquisition, A.A.A.; Investigation, A.-B.A.-O.; Methodology, M.O. and W.S.S.; Project administration, T.A.; Software, W.S.S. and A.A.-K.; Supervision, A.A.A. and T.A.; Validation, A.Y.B.H.A.; Visualization, A.A.A. and A.A.-K.; Writing — original draft, W.S.S. and T.A.; Writing—review \& editing, T.A. All authors have read and agreed to the published version of the manuscript.

Funding: This research was funded by the Deanship of Scientific Research at King Saud University, through Research Group No. RGP-1438-040.

Conflicts of Interest: The authors declare no conflict of interest.

\section{References}

1. Li, S.; McCarthy, S. Further investigations on the hydrolytic degradation of poly(DL-lactide). Biomaterials 1999, 201, 35-44. [CrossRef]

2. Tsuji, H.; Miyauchi, S. Poly(L-lactide): VI effects of crystallinity on enzymatic hydrolysis of poly(L-lactide) without free amorphous region. Polym. Degrad. Stab. 2001, 71, 415-424. [CrossRef]

3. Tsuji, H. In vitro hydrolysis of blends from enantiomeric poly(lactide)s. Biomaterials 2003, 24, 537-547. [CrossRef]

4. Karst, D.; Yang, Y. Molecular modeling study of the resistance of PLA to hydrolysis based on the blending of PLLA and PDLA. Polymer 2006, 47, 4845-4850. [CrossRef]

5. Mokwena, K.K.; Tang, J. Ethylene vinyl alcohol. Critical. Rev. Food Sci. Nutr. 2012, 52, 640-650. [CrossRef] [PubMed]

6. Isella, F.; Canellas, E.; Bosetti, O.; Nerin, C. Migration of non intentionally added substances from adhesives by UPLC-Q-TOF/MS and the role of EVOH to avoid migration in multilayer packaging materials. J. Mass Spectrom. 2013, 48, 430-437. [CrossRef]

7. Tang, Y.; Guo, L.; Huang, L.; Liu, X. Mechanical and structural analysis of poly(vinyl alcohol)/poly(ethylene-co-vinyl alcohol) blend films. Polym. Mater. Sci. Eng. 2015, 31, 57-61.

8. Guerra, N.; Barbani, L.; Lazzeri, L.; Lelli, L.; Palla, M.; Rizzo, C. The activation of human plasma prekallikrein as a hemocompatibility test for biomaterials. II. Contact activation by EVAL and EVAL- SMA copolymers. J. Biomater. Sci. 1995, 4, 643-652.

9. Tomita, K.; Kojoh, K.; Suzuki, A. Isolation of thermophiles assimilating poly(ethylene-co-vinyl alcohol). J. Ferment. Bioengin. 1997, 84, 400-402. [CrossRef] 
10. Mejía, G.A.I.; López, O.B.L.; Sierra, L. Biodegradation of poly(vinylalcohol-co-ethylene) with the fungus Phanerochaete chrysosporium. Mater. Res. Innov. 2001, 4, 148-154. [CrossRef]

11. Lopez, B.L.; Mejia, A.I.; Sierra, L. Biodegradability of poly(vinylalcohol). Polym. Eng. Sci. 1999, 39, $1346-1352$.

12. Mejía, G.A.I.; López, O.B.L.; Mulet, P.A. Biodegradation of poly(vinylalcohol) with enzymatic extracts of phanerochaete chrysosporium. Macromol. Symp. 1999, 148, 131-147. [CrossRef]

13. Matsumoto, Y.; Mukai, M.; Arihara, K.; Saito, T.; Kumagai, H. Ethylene-vinyl alcohol copolymer dialyzer membrane reduces protein oxidation in hemodialysis patients. Ren. Fail. 2011, 33, 382-387. [CrossRef] [PubMed]

14. Bonomini, M.; Pavone, B.; Sirolli, V.; Del Buono, F.; Di Cesare, M.; Del Boccio, P.; Amoroso, L.; Di Ilio, C.; Sacchetta, P.; Federici, G.; et al. Proteomics characterization of protein adsorption onto hemodialysis membranes. J. Proteome Res. 2006, 10, 2666-2674. [CrossRef]

15. Ishida, M. Blood compatibility of ethylene-vinyl alcohol copolymer dialyzers. Cells 2005, 37, 30-34.

16. Ito, S.; Suzuki, C.; Tsuji, T. Platelet activation through interaction with hemodialysis membranes induces neutrophils to produce reactive oxygen species. J. Biomed. Mater. Res. 2006, 77A, 294-303. [CrossRef]

17. Sirolli, V.; Ballone, E.; Di Liberato, L.; Di Mascio, R.; Cappelli, P.; Albertazzi, A.; Bonomini, M. Leukocyte adhesion molecules and leukocyte- platelet interactions during hemo-dialysis: Effect of different synthetic membranes. Int. J. Artif. Org. 1999, 22, 536-542. [CrossRef]

18. Young, T.H.; Lin, C.W.; Cheng, L.P.; Hsieh, C.C. Preparation of EVAL membranes with smooth and particulate morphologies for neuronal culture. Biomaterials 2001, 22, 1771-1777. [CrossRef]

19. Fukuzaki, H.; Yoshida, M.; Asano, M.; Kumakura, M. Synthesis of copoly(D,L-lactic acid) with relatively low molecular weight and in vivo degradation. Eur. Polym. J. 1989, 25, 1019-1026. [CrossRef]

20. Gilding, D.K.; Reed, A.M. Biodegradable polymers for use in surgery polyglycolid/poly(lactic acid) homo and copolymers. Polymer 1979, 20, 1459-1464. [CrossRef]

21. Engineer, C.; Parikh, J.; Raval, A. Review on hydrolytic degradation behavior of biodegradable polymers from controlled drug delivery system. Trends Biomater. Artif. Organs. 2011, 25, 79-85.

22. Makadia, H.K.; Siegel, S.J. Poly lactic-co-glycolic acid (PLGA) as biodegradable controlled drug delivery carrier. Polymers 2011, 3, 1377-1397. [CrossRef] [PubMed]

23. Merkli, A.; Tabatabay, C.; Gurny, R.; Heller, J. Biodegradable polymers for the controlled release of ocular drugs. Progr. Polym. Sci. 1998, 23, 563-580. [CrossRef]

24. Athanasiou, K.A.; Niederauer, G.G.; Agrawal, M. Sterilization, toxicity, biocompatibility and clinical applications of polylactic acid/polyglycolic acid copolymers. Biomaterials 1996, 17, 93-102. [CrossRef]

25. Danhier, F.; Ansorena, E.; Silva, J.M.; Coco, R.; Le Breton, A.; Préat, V. PLGA-based nanoparticles: An overview of biomedical applications. J. Contr. Rel. 2012, 161, 505-522. [CrossRef]

26. Ladewig, K. Drug delivery in soft tissue engineering. Expert. Opin. Drug Deliv. 2011, 8, 1175-1188. [CrossRef]

27. Mikos, A.G.; Herring, S.W.; Ochareon, P.; Elisseeff, J.; Lu, H.H.; Kandel, R.; Schoen, F.J.; Toner, M.; Mooney, D.; Atala, A.; et al. Engineering complex tissues. Tissue Eng. 2006, 12, 3307-3339. [CrossRef]

28. Yilgor, P.; Hasirci, N.; Hasirci, V. Sequential BMP-2/BMP-7 delivery from polyester nanocapsules. J. Biomed. Mater. Res. A 2010, 93, 528-536. [CrossRef]

29. Tuli, R.; Li, W.J.m.; Tuan, R.S. Current state of cartilage tissue engineering. Arthritis Res. Ther. 2003, 5, $235-238$. [CrossRef]

30. Atala, A.; Robert, P.L. (Eds.) Methods of Tissue Engineering; Academic Press: Cambridge, MA, USA, 2002.

31. Attawia, M.A.; Herbert, K.M.; Laurencin, C.T. Osteoblast like cell adherence and migration through 3-dimensional porous polymer matrices. Biochem. Biophys. Res. Commun. 1995, 213, 639-644. [CrossRef]

32. Bendix, D. Chemical synthesis of polylactide and its copolymers for medical applications. Polym. Degrad. Stab. 1998, 59, 129-135. [CrossRef]

33. Wu, X.S.; Wang, N. Synthesis, characterization, biodegradation, and drug delivery application of biodegradable lactic/glycolic acid polymers. Part II: Biodegradation. J. Biomater. Sci. Polym. Ed. 2001, 12, 21-34. [CrossRef] [PubMed]

34. Kenawy, E.; Laymana, E.J.M.; Watkinsa, J.R.; Bowlinb, G.L.; Matthewsb, J.A.; Simpsonc, D.G.; Wnek, G.E. Electrospinning of poly(ethylene-co-vinyl alcohol) fibers. Biomaterials 2003, 24, 907-913. [CrossRef]

35. Kit, K.M.; Schultz, J.M.; Gohil, R.M. Morphology and barrier properties of blends of poly(ethylene terephthalate) and poly(ethylene 2,6 naphthalate) with poly(ethylene-co-vinyl alcohol). Polym. Eng. Sci. 1995, 35, 680-692. [CrossRef] 
36. Matsumura, K.; Hyon, S.H.; Nakajima, N.; Iwata, H.; Watazu, A.; Tsutsumi, S. Surface modification of poly(ethylene-co-vinyl alcohol): Hydroxyaptite immobilization and control of periodontal ligament cells differentiation. Biomaterials 2004, 25, 4817-4824. [CrossRef]

37. Wang, B.; Chao, X.; Li, Y.; Reid, S.R. Tensile strength of electrospun poly(vinylalcohol-co-ethylene) nanofibre sheets. Key Eng. Mater. 2013, 535-536, 215-218. [CrossRef]

38. Luo, D.-J.; Shao, H.-J.; Wei, F.-J.; Zhang, K.-Z.; Cui, Z.-Y.; Yu, J.; Qui, S.-H. Morphology and isothermal crystallization kinetics of polypropylene/poly(ethylene-co-vinylalcohol) blends. Inter. Polym. Process. 2019, 34, 195-208. [CrossRef]

39. Saeed, W.S.; Al-Odayni, A.-B.; Alghamdi, A.A.; Al-Owais, A.A.; Semlali, A.; Aouak, T. Miscibility of poly(ethylene-co-vinylalcohol)/poly( $\delta$-valerolactone) blend and tissue engineering scaffold fabrication using naphtalene as porogen. Polym. Plast. Technol. Engin. 2019, 58, 1-23.

40. Zhu, B.-D.; Zhang, J.-Y.; Lin, C.-H.; Chen, H.-L.; Wang, J. Nonisothermal crystallization kinetics of ethylene vinyl alcohol copolymer with poly(oxypropylene)diamine intercalated montmorrilonite. J. Macromol. Sci. Part B 2018, 57, 333-347. [CrossRef]

41. Soria, V.; Gomez, C.M.; Falo, M.; Abad, C.; Campos, A. Relative strength of H-bonding groups on biodegradable polymer-based blends in solution. J. Appl. Polym. Sci. 2006, 100, 900-910. [CrossRef]

42. Huggins, M.L. The viscosity of dilute solutions of long-chain molecules. IV. Dependence on concentration. J. Am. Chem. Soc. 1942, 64, 2716-2720. [CrossRef]

43. Sun, Z.; Wang, W.; Fung, Z. Criterion of polymer-polymer miscibility determined by viscometry. Eur. Polym. J. 1992, 28, 1259-1261. [CrossRef]

44. Zhang, Y.; Shams, T.; Harker, A.H.; Parhizkar, M.; Edirisinghe, M. Effect of copolymer composition on particle morphology and release behavior in vitro using progesterone. Mater. Des. 2018, 159, 57-67. [CrossRef]

45. Takahashi, M.; Tashiro, K.; Amiya, S. Crystal structure of ethylene vinyl alcohol copolymers. Macromolecules 1999, 32, 5860-5871. [CrossRef]

46. Cerrada, M.L.; Perez, E.; Perena, J.M.; Benavente, R. Wide angle X-ray diffraction study of the phase behavior of vinyl alcohol-ethylene copolymers. Macromolecules 1998, 31, 2559-2564. [CrossRef]

47. Weng, M.; Qiu, Z. Crystallization kinetics and morphology of novel miscible crystalline/amorphous polymer blends of biodegradable poly(butylene succinate-co-butylene carbonate) and poly(vinyl phenol). Ind. Eng. Chem. Res. 2013, 52, 10198-10205. [CrossRef]

48. Chou, H.-J. Poly(trimethylene terephthalate)/amorphous poly(ethylene terephthalate) blends. Polym. Eng. Sci. 2007, 47, 2005-2011. [CrossRef]

49. Freire, E.; Bianchi, O.; Martins, J.N.; Montteiro, E.E.C.; Forte, M.M.C. Non-isothermal crystallization of PVDF/PMMA blends processed in low and high shear mixers. J. Non Cryst. Solid. 2012, 358, 2674-2681. [CrossRef]

50. Hoffman, J.D.; Weeks, J. Melting process and the equilibrium melting temperature of polychlorotrifluoroethylene. J. Res. Natl. Bur. Stand. A Phys. Chem. 1962, 66A, 13-28. [CrossRef]

51. Alvarez, V.A.; Kenny, J.M.; Vázquez, A. Isothermal crystallization of poly(vinyl alcohol-co-ethylene). J. Appl. Polym. Sci. 2003, 89, 1071-1077. [CrossRef]

52. Nishi, T.; Wang, T.T. Melting point depression and kinetic effects of cooling on crystallization in poly(vinylidene fluoride)-poly(methyl methacrylate) mixtures. Macromolecules 1975, 8, 909-915. [CrossRef]

53. Young, T.H.; Lai, J.Y.; You, W.M.; Cheng, L.P. Equilibrium phase behavior of the membrane forming water-DMSO-EVAL system. J. Membr. Sci. 1997, 128, 55-65. [CrossRef]

54. Akiba, I.; Akiyama, S. Phase behavior of poly(ethylene-co-vinyl alcohol)/nylon 6-12 blends. Polym. J. 1994, 26, 873-979. [CrossRef]

55. Kuo, S.W.; Chang, F.C. The study of miscibility and hydrogen bonding in blends of phenolics with poly(E-caprolactone. Macromol. Chem. Phys. 2001, 202, 3112-3119. [CrossRef]

56. Aouak, T.; AlArifi, A.S.; Ouladsmane, M. Miscibility and crystallization behavior of poly(ethylene-co-vinylalcohol)/poly(maleic anhydride-alt-ethylene) blend. J. Appl. Polym. Sci. 2012, 125, 2262-2270. [CrossRef]

57. Guo, Q.; Groeninckx, G. Crystallization kinetics of poly( $\varepsilon$-caprolactone) in miscible thermosetting polymer blends of epoxy resin and poly( $\varepsilon$-caprolactone). Polymer 2001, 42, 8647-8655. [CrossRef]

58. Ozawa, T. Kinetics of non-isothermal crystallization. Polymer 1971, 12, 150-158. [CrossRef] 
59. Liu, X.H.; Wu, Q.J.; Berglund, L.A.; Qi, Z.N. Investigation on unusaual crystallization behavior in polyamide 6/montmorillonite nanocomposites. Macromol. Mater. Eng. 2002, 287, 515-522. [CrossRef]

60. Chen, Z.; Yao, C.; Yang, G. Non isothermal crystallization behavior, and morphology of poly(trimethylene terephthalate)/polyethylene glycol copolymers. Polym. Test. 2012, 31, 393-403. [CrossRef]

61. Run, M.; Song, A.; Wang, Y.; Yao, C. Melting, crystallization behaviors, and nonisothermal crystallization kinetics of PET/PTT/PBT ternary blends. J. Appl. Polym. Sci. 2007, 104, 3459-3468. [CrossRef]

62. Dhandapani, S.; Nayak, S.K.; Mohanty, S. Non-isothermal crystallization kinetics and activation energy of bio-based poly(trimethylene terephthalate)/poly(butylene adipate-co-terephthalate) polyester blend. Polym. Sci. Ser. A 2015, 57, 628-634. [CrossRef]

63. Hammami, A.; Spruiell, J.E.; Mohrotra, A.K. Quiescent non isothermal crystallization kinetics of isotactic polypropylenes. Polym. Eng. Sci. 1995, 35, 797-804. [CrossRef]

64. Jeziorny, A. Parameters characterizing the kinetics of the non-isothermal crystallization of poly(ethylene terephtalate) determined by DSC. Polymer 1978, 19, 1142-1144. [CrossRef]

65. Ziabicki, A. Theoretical analysis of oriented and nonisothermal crystallization I. Phenomenological considerations, isothermal crystallization accompanied by simultaneous orientation or disorientation. Colloid. Polym. Sci. 1974, 252, 207-221. [CrossRef]

66. Ziabicki, A. Theoretical analysis of oriented and non-isothermal cyrstallization II. Extension of the Kolmogoroff-Avrami-Evans theory onto processes with variable rates and mechanisms. Colloid Polym. Sci. 1974, 252, 433-447. [CrossRef]

67. Liu, T.; Mo, Z.; Wang, S.; Zhang, H. Non-isothermal melt and cold crystallization kinetics of poly(aryl ether ether ketone ketone). Polym. Eng. Sci. 1997, 37, 568-575. [CrossRef]

68. Avrami, M. Kinetics of phase change I general theory. J. Chem. Phys. 1939, 7, 1103-1112. [CrossRef]

69. Alvarez, V.A.; Stephani, P.M.; Vazquez, A. Non-isothermal crystallization of polyvinylalcohol-co-ethylene. J. Therm. Anal. Cal. 2005, 79, 187-193. [CrossRef]

70. Pratt, C.F.; Hobbs, S.Y. Comparative study of crystallization rates by DSC and depolarization microscopy. Polymer 1976, 17, 12-16. [CrossRef]

71. Gupta, A.K.; Rana, S.K.; Deopura, B.L. Crystallization kinetics of high-density polyethylene/linear low-density polyethylene blend. J. Appl. Polym. Sci. 1994, 51, 231-239. [CrossRef]

72. Kissinger, H.E. Variation of peak temperature with heating rate in differential thermal analysis. J. Res. Natl. Bur. Stand. 1956, 57, 217-221. [CrossRef]

73. Alvarez, V.A.; Ruseckaite, V.A.; Vázquez, A. Kinetic analysis of thermal degradation in poly(ethylene-vinyl alcohol) copolymers. J. Appl. Polym. Sci. 2003, 90, 3157-3163. [CrossRef]

74. Park, J.S.; Kang, S.K. A study on surface, thermal and mechanical properties of absorbable PLGA plate. Int. J. Control. Automat. 2013, 6, 73-82. [CrossRef]

75. Holland, B.J.; Hay, J.N. The thermal degradation of poly(vinyl alcohol). Polymer 2001, 42, 6775-6783. [CrossRef]

76. Sivalingam, G.; Madras, G. Thermal degradation of binary physical mixtures and copolymers of poly(e-caprolactone), poly( d, l-lactide), poly(glycolide). Polym. Degrad. Stab. 2004, 84, 393-398. [CrossRef]

77. McNeill, I.C.; Leiper, H.A. Degradation studies of some polyesters and polycarbonates-2. Polylactide: Degradation under isothermal conditions, thermal degradation mechanism and photolysis of the polymer. Polym. Degrad. Stab. 1985, 11, 309-326. [CrossRef]

78. McNeill, I.C.; Leiper, H.A. Degradation studies of some polyesters and polycarbonates: 3-polyglycolide. Polym. Degrad. Stab. 1985, 12, 373-385. [CrossRef]

(C) 2020 by the authors. Licensee MDPI, Basel, Switzerland. This article is an open access article distributed under the terms and conditions of the Creative Commons Attribution (CC BY) license (http://creativecommons.org/licenses/by/4.0/). 